\title{
Mechanical Properties and Durability of Latex-Modified Fiber-Reinforced Concrete: A Tunnel Liner Application
}

\author{
Joo-Ha Lee, ${ }^{1}$ Hwang-Hee Kim, ${ }^{2}$ Sung-Ki Park, ${ }^{2}$ Ri-On Oh, ${ }^{2}$ Hae-Do Kim, ${ }^{3}$ and \\ Chan-Gi Park $\mathbb{1}^{4}$ \\ ${ }^{1}$ Department of Civil Engineering, University of Suwon, Hwaseong 18323, Republic of Korea \\ ${ }^{2}$ Research Center, Contecheng Co., Ltd., Seongnam 13636, Republic of Korea \\ ${ }^{3}$ Rural Research Institute, Korea Rural Community Corporation, Ansan 15634, Republic of Korea \\ ${ }^{4}$ Department of Rural Construction Engineering, Kongju National University, Yesan 32439, Republic of Korea
}

Correspondence should be addressed to Chan-Gi Park; cgpark@kongju.ac.kr

Received 22 August 2017; Revised 8 November 2017; Accepted 14 November 2017; Published 21 January 2018

Academic Editor: Young Hoon Kim

Copyright ( $\odot 2018$ Joo-Ha Lee et al. This is an open access article distributed under the Creative Commons Attribution License, which permits unrestricted use, distribution, and reproduction in any medium, provided the original work is properly cited.

This study assessed the mechanical properties and durability of latex-modified fiber-reinforced segment concrete (polyolefinbased macrosynthetic fibers and hybrid fiber-macrosynthetic fiber and polypropylene fiber) for a tunnel liner application. The tested macrosynthetic fiber-reinforced concrete has a better strength than steel fiber-reinforced concrete. The tested concrete with blast furnace slag has a higher chloride ion penetration resistance (less permeable), but its compressive and flexural strengths can be reduced with blast furnace slag content increase. Also, the hybrid fiber-reinforced concrete has higher compressive strength, flexural strength, chloride ion water permeability resistance, impact resistance, and abrasion resistance than the macrosynthetic fiber-reinforced concrete. The modified fiber improved the performance of concrete, and the hybrid fiber was found to control the formation of micro- and macrocracks more effectively. Therefore, overall performance of the hybrid fiber-reinforced concrete was found superior to the other fiber-reinforced concrete mixes tested for this study. The test results also indicated that macrosynthetic fiber could replace the steel fiber as a concrete reinforcement.

\section{Introduction}

Utility tunnels in urban areas are generally constructed using drill and blast and mechanized tunneling methods. Although tunnel excavation using the drill and blast method is economically feasible, environmental restrictions and ground conditions must be carefully considered for a tunnel construction method selection [1]. Noise, vibration, impact on the existing infrastructures, and environmental issues are typical concerns for the tunnel construction in urban spaces $[1,2]$. For these reasons, a mechanized tunneling (e.g., shield TBM) is more favorable for an urban tunneling (e.g., subways, electric power, communications, and water tunnels) [2, 3]. Shield TBM tunnels typically use steel and concrete segmental liner for tunnel supports. Steel segments were initially used exclusively [4]. However, as concrete performance improved, reinforced concrete (RC) segmental liners have been increasingly used due to their enhanced corrosion resistance and cost-effectiveness compared to steel liners [4]. In urban areas, tunnels are usually located within the public road right of way (ROW). They tend to follow the road's alignment, and relatively sharp curves are also required to minimize tunnel intrusions into private properties [1]. For this case, edges of a reinforced concrete (RC) segmental liner can be damaged by the TBM thrust force and load eccentricity. Therefore, considerations have been given to the steel segmental liners to mitigate this type of damage. However, steel segmental liners are known to be corrosive when they are exposed to an aggressive environment (Figure 1).

Recent studies have explored alternatives to minimize the steel reinforcement of RC segmental liner using steel fiber reinforcement $[4,5]$. Steel fiber-reinforced concrete 

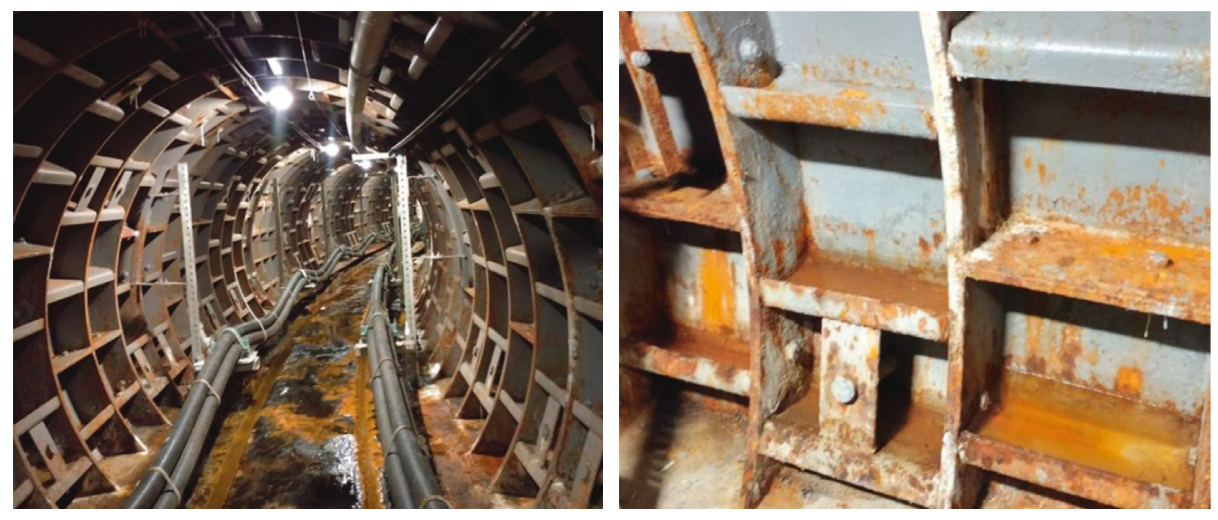

Figure 1: Corrosion of steel segments.

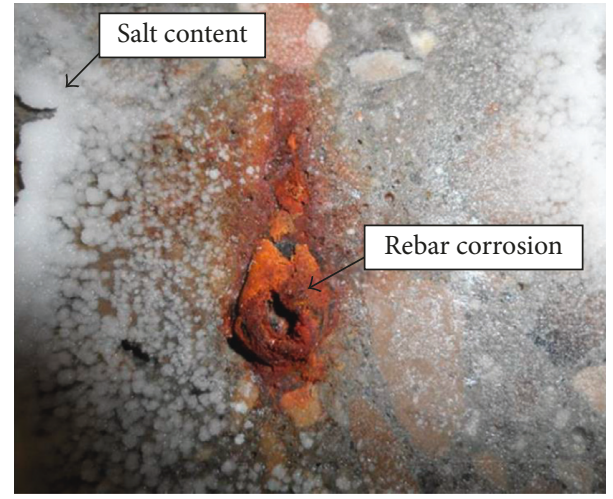

(a)

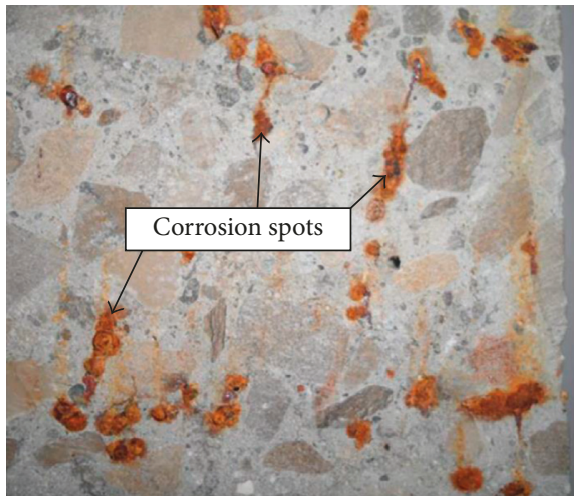

(b)

FIGURE 2: Corrosion of steel rebar and steel fiber exposed to $10 \% \mathrm{Cl}^{-}$solution. (a) RC beam specimen. (b) SFRC beam specimen.

segmental liners have a better performance than typical RC segmental liners. However, durability of the steel fiberreinforced concrete segmental liner was questioned due to the internal corrosion of the steel reinforcement (Figure 2) [6]. According to the study done by Abbas, RC and steel fiber-reinforced concrete (SFRC) segments can be corroded when they are exposed to a chloride ion environment [6]. There are two mitigation measures to the corrosion issue of steel rebar and steel fiber reinforcement: (1) improve the water permeability resistance by compacting the concrete and/or (2) use noncorrosive reinforcing materials. This study evaluated the utilization of noncorrosive polyolefinbased macrosynthetic fiber and hybrid fiber as a replacement of steel fiber and steel reinforcement commonly used in concrete segmental tunnel liners. Latex and blast furnace slag (an industrial by-product) were also used to improve the water permeability resistance. Many studies have discussed the use of polyolefin-based macrosynthetic fiber in various applications such as marine structures, shotcrete, and concrete tunnel liners due to its corrosion resistance and higher impact/static strength than steel fiber. These properties translate to better corrosion resistance and higher rebound stability than steel fiber in shotcrete [7-10]. However, the fluidity decreases as volume fraction increases due to poorer fiber dispersibility in fiber-reinforced concrete, which leads to poorer segmental concrete liner performance [11, 12]. This study used latex to increase the fluidity and water permeability resistance. When latex is added to the concrete mix, it improves the water permeability resistance due to the formation of a latex film, fiber dispersibility, and fluidity of fiber-reinforced concrete $[13,14]$. Also, the waterproofness of concrete containing fine particles of blast furnace slag improves as the generated calcium-silicate-hydrate $(\mathrm{C}-\mathrm{S}-\mathrm{H})$ gel improves the pore system and subsequently the sulfate and chloride ion penetration resistance [15-17]. To evaluate the feasibility of replacing commonly used steel fiber-reinforced concrete with latex-modified fiber-reinforced concrete for a tunnel liner application, this study tested the compressive strength, flexural strength, and chloride ion penetration as a function of volume fraction with fine particles of blast furnace slag, steel fiber, and macrosynthetic fiber. A mix suitable for a latexmodified segment concrete was used, to which macrosynthetic fiber and a hybrid fiber, consisting of a combination of macrosynthetic fiber + polypropylene fiber, were added. The reinforced concrete was then tested for compressive strength, flexural strength, chloride ion penetration, impact strength, and abrasion resistance. Previous research 
TABle 1: Properties of cement.

\begin{tabular}{|c|c|c|c|c|c|c|c|c|}
\hline \multirow[t]{2}{*}{ Type of cement } & \multirow[t]{2}{*}{ Fineness $\left(\mathrm{cm}^{2} / \mathrm{g}\right)$} & \multirow[t]{2}{*}{ Density $\left(\mathrm{g} / \mathrm{mm}^{3}\right)$} & \multirow[t]{2}{*}{ Stability (\%) } & \multicolumn{2}{|c|}{ Setting time } & \multicolumn{3}{|c|}{$\begin{array}{c}\text { Compressive strength } \\
(\mathrm{MPa})\end{array}$} \\
\hline & & & & Initial (min) & Final (min) & 3 days & 7 days & 28 days \\
\hline ASTM type 1 & 3200 & 3.15 & 0.02 & 220 & 400 & 20.3 & 30.2 & 38.7 \\
\hline
\end{tabular}

indicated that the hybrid fiber is effective at macro- and microinternal crack formation prevention in segmental concrete liners.

\section{Materials}

2.1. Materials. This study used ASTM Type I cement, and its properties are given in Table 1. Fine particles of blast furnace slag were added to improve the durability and waterproofness of concrete. The blast furnace slag composition is listed in Table 2. Crushed aggregate having a maximum size of $25 \mathrm{~mm}$ was used as the coarse aggregate, and Table 3 gives the physical properties of the coarse aggregate. The fine aggregate had a density of $2.62 \mathrm{~g} / \mathrm{mm}^{3}$. For the reinforcing fiber, bundled end-hook-type steel fiber $(30 \mathrm{~mm}$ (length) $\times 0.5 \mathrm{~mm}$ (diameter) $)$ and polyolefinbased macrosynthetic fiber (30 mm (length) $\times 1 \mathrm{~mm}$ (diameter)) were used; Table 4 and Figure 3 provide details. The polyolefin-based macrosynthetic fiber (macrosynthetic fiber) is a monofilament fiber with polypropylene and polyethylene combined (Nycon Materials Co., Seoul, Republic of Korea). In this study, polypropylene fiber was applied. The polypropylene microfibers (polypropylene fiber) consisted of $100 \%$ percent virgin homopolymer polypropylene multifilament fibers containing no reprocessed olefin materials.

The report published by the 548 Technical Committee of the American Concrete Institute (ACI) indicated that pores ranging from 10 to $1000 \mathrm{~nm}$ in diameter damage concrete in the long term through a capillary effect [18]. Polymers with a particle size of $100 \mathrm{~nm}$ effectively fill these internal pores. In this study, it was difficult to ensure the pore filling during the mixing or sample fabrication due to low initial fluidity caused by the fiber reinforcement. Styrene-butadiene (SB) latex was used to improve durability and initial fluidity [18]. Table 5 summarizes the SB latex properties.

2.2. Mix Proportions. This study evaluated the performance of latex-modified fiber-reinforced concrete as a function of type and volume fraction of reinforcing fiber and the use of fine particles of blast furnace slag. The mechanical properties and durability of the concrete were measured for the mixes containing steel fiber and macrosynthetic fiber with fiber volume fractions at $0.0,0.25,0.5$, and $1.0 \%$ and with fine particles of blast furnace slag substituted at $30 \%$. Latex was included at $10 \%$ of the binder weight. The design compressive strengths of the concrete mixes were 40 and $60 \mathrm{MPa}$ at a material age of 28 days. Tables 6 and 7 give the mix designs.
TABle 2: Chemical compositions of blast furnace slag.

\begin{tabular}{lccccccc}
\hline \multicolumn{7}{c}{ Chemical composition (\%) } \\
$\mathrm{SiO}_{2}$ & $\mathrm{Al}_{2} \mathrm{O}_{3}$ & $\mathrm{Fe}_{2} \mathrm{O}_{3}$ & $\mathrm{CaO}$ & $\mathrm{MgO}$ & $\mathrm{MnO}$ & $\mathrm{TiO}$ & $\mathrm{S}$ \\
\hline 33.1 & 13.9 & 0.29 & 42.4 & 6.1 & 0.4 & 0.96 & 0.66 \\
\hline
\end{tabular}

TABle 3: Physical properties of coarse aggregate.

\begin{tabular}{|c|c|c|c|c|c|}
\hline \multirow[b]{2}{*}{ Type of aggregate } & \multicolumn{3}{|c|}{ Specific density $\left(\mathrm{g} / \mathrm{mm}^{3}\right)$} & \multirow[b]{2}{*}{$\begin{array}{c}\text { Absorption } \\
(\%)\end{array}$} & \multirow[b]{2}{*}{ FM } \\
\hline & Bulk & $\begin{array}{c}\text { Bulk } \\
\text { (SSD) }\end{array}$ & Apparent & & \\
\hline $\begin{array}{l}\text { Crushed coarse } \\
\text { aggregate }\end{array}$ & 2.80 & 2.65 & 2.83 & 0.35 & 6.5 \\
\hline
\end{tabular}

\section{Test Methods}

The compressive strength, flexural strength, and chloride ion penetration resistance of the latex-modified fiberreinforced segment concrete were measured using standard test methods. Impact resistance and abrasion resistance tests were also carried out to measure the durability of the mixes.

3.1. Compressive Strength. Compressive strength was determined in accordance with ASTM C 39 "Testing Methods for Compressive Strength of Concrete Standard" [19]. Specimens of dimensions $100 \mathrm{~mm}$ (diameter) $\times 200 \mathrm{~mm}$ (length) were made. Three specimens were tested at the material age of 28 days. The specimen was located at the center of the platen in the universal testing machine and loaded at constant speed until failure. The maximum load for each specimen was divided by its cross-sectional area, and the average value was reported as the compressive strength. Specimens were cured for 1 day at $23 \pm 2^{\circ} \mathrm{C}$ and a relative humidity of $50 \%$, followed by water curing in a constant temperature bath at $23 \pm 2^{\circ} \mathrm{C}$. Testing was done in duplicate.

3.2. Flexural Strength. Flexural strength was evaluated using the ASTM C 496 "Testing Methods for Flexural Strength of Concrete Standard" [20]. Concrete was placed in a rectangular mold $(100 \mathrm{~mm} \times 100 \mathrm{~mm} \times 400 \mathrm{~mm})$ to form three specimens for this test at the material age of 28 days. After initial curing, the specimens were immersed in a constant temperature water bath at $23 \pm 2^{\circ} \mathrm{C}$. Testing was done in duplicate.

3.3. Chloride Ion Penetration. Permeability is the most important contributor to the strength and durability of concrete. Increased permeability lowers the strength via 
TABle 4: Properties of fibers.

\begin{tabular}{|c|c|c|c|c|c|c|c|}
\hline \multicolumn{2}{|c|}{ Type of fiber } & $\begin{array}{l}\text { Elastic modulus } \\
\text { (GPa) }\end{array}$ & $\begin{array}{l}\text { Density } \\
\left(\mathrm{g} / \mathrm{mm}^{3}\right)\end{array}$ & $\begin{array}{l}\text { Length } \\
(\mathrm{mm})\end{array}$ & $\begin{array}{l}\text { Diameter } \\
(\mathrm{mm})\end{array}$ & $\begin{array}{l}\text { Tensile strength } \\
(\mathrm{MPa})\end{array}$ & $\begin{array}{l}\text { Aspect ratio } \\
(L / d)\end{array}$ \\
\hline Steel & Bundled type & 200 & 7.8 & 30 & 0.5 & 1100 & 60 \\
\hline Polypropylene & Fibrillated bundle type & 4 & 0.91 & 6 & 0.1 & 600 & 60 \\
\hline Macrosynthetic & $\begin{array}{l}\text { Crimped type } \\
\text { (monofilament) }\end{array}$ & 10 & 0.91 & 30 & 1 & 550 & 30 \\
\hline
\end{tabular}

crack expansion and reduces the durability through freezing, thawing, and abrasion. In this study, a permeability test was conducted in accordance with standard ASTM C 1202-94 [21]. Two cylindrical specimens (100 mm (diameter) $\times 200 \mathrm{~mm}$ (length)) were prepared for each composition and tested at the material age of 28 days. The centers of the specimens were lowered to a thickness of $50 \mathrm{~mm}$ and then placed in a desiccator. Vacuum was applied for 3 hours to remove the trapped air, and then water was introduced into the desiccator to saturate the specimens with water. The vacuum was reapplied for 1 hour. The vacuum pump was then turned off, and the specimens were maintained fully immersed in water for $18 \pm 1$ hours. Following this process, a specimen was fixed in an applied voltage cell, where the positive pole was filled with $0.3 \mathrm{~N} \mathrm{NaOH}$ solution, and the negative pole was filled with $3 \% \mathrm{NaOH}$ solution. A potential of $60 \mathrm{~V}$ was applied, and the current was measured over a 6-hour period. The test was repeated twice with three specimens having the material age of 28 days. Figure 4 shows the chloride ion penetration resistance setup. Table 8 (from the ASTM standard) ranks the chloride ion permeability level as a function of the charge passed.

3.4. Impact Resistance. The ACI Committee 544 Test Method was used to evaluate impact resistance. According to this method, a rigid body of dimensions $150 \mathrm{~mm}$ (diameter) $\times 60 \mathrm{~mm}$ (length) is freely dropped [22]. Three specimens were produced for each material age, cured for 1 day in a curing room $\left(23 \pm 2^{\circ} \mathrm{C}, 50 \%\right.$ relative humidity) and then cured in a water bath at a constant temperature of $23 \pm 2^{\circ} \mathrm{C}$. The test was repeated twice for three specimens at the material age of 28 days. Figure 5 shows the device used for the impact resistance test.

3.5. Abrasion Resistance. Four cylindrical specimens were made with dimensions $150 \mathrm{~mm}$ (diameter) $\times 300 \mathrm{~mm}$ (length) in accordance with the ASTM C 944 standard [23]. The specimens were cured in a curing room at $23 \pm 2^{\circ} \mathrm{C}$ and a relative humidity of $50 \%$ for 1 day, demolded, and then cured in water for 28 days in a constant temperature bath at $23 \pm 2^{\circ} \mathrm{C}$. The abrasion test was performed in duplicate. The test setup is shown in Figure 6.

\section{Results and Discussion}

4.1. Compressive Strength. Figure 7 shows the compressive strength results for the mix formulations containing

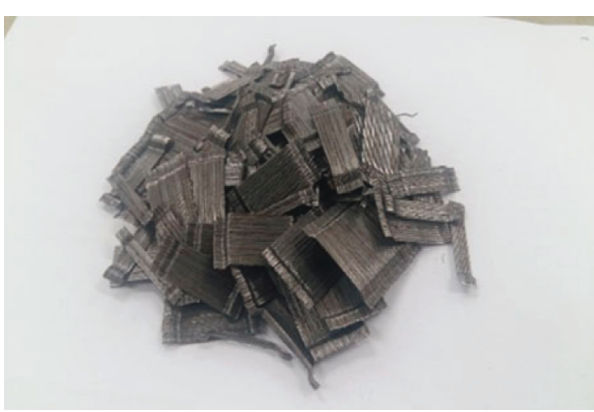

(a)

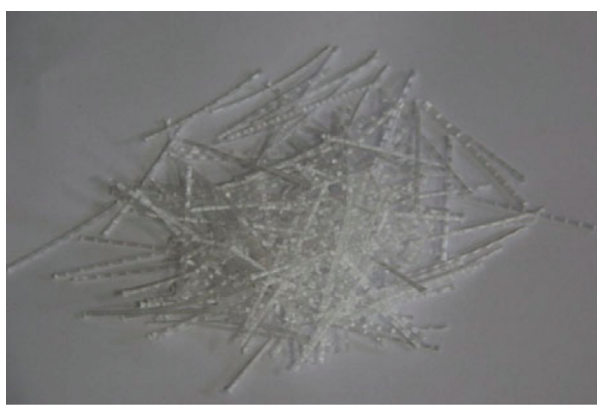

(b)

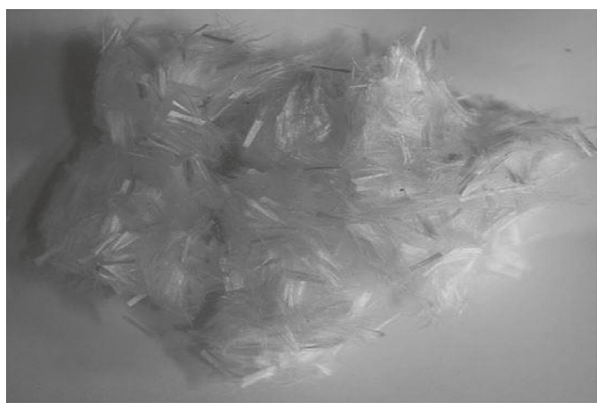

(c)

FIGURE 3: Geometry of reinforcing fibers. (a) Bundled endhook-type steel fibers. (b) Macrosynthetic fibers. (c) Polypropylene fiber.

various amounts of fine particles of blast furnace slag. The blast furnace slag content increase in the mixes lowered the compressive strength of concrete, and similar results were found regardless of the fiber type or volume fraction for all design strengths of 40 and $60 \mathrm{MPa}$. The fine particles of blast furnace slag behaved as a quasi-pozzolanic material. The design strength was achieved for all mixes.

Figures 8 and 9 show the compressive strength results as a function of reinforcing fiber type. This study evaluated the 
TABle 5: Properties of SB latex.

\begin{tabular}{lccccccc}
\hline Solid content (\%) & Styrene content (\%) & Butadiene content $(\%)$ & $\mathrm{pH}$ & $\begin{array}{c}\text { Density } \\
\left(\mathrm{g} / \mathrm{mm}^{3}\right)\end{array}$ & $\begin{array}{c}\text { Surface tension } \\
(\text { dyne/cm })\end{array}$ & $\begin{array}{c}\text { Particle } \\
\text { size }(\AA)\end{array}$ & $\begin{array}{c}\text { Viscosity } \\
(\mathrm{cps})\end{array}$ \\
\hline 49 & $34 \pm 1.5$ & $66 \pm 1.5$ & 11.0 & 1.02 & 30.57 & 1700 & 42 \\
\hline
\end{tabular}

TABle 6: Mixture design of segment $\left(f_{\mathrm{ck}}=40 \mathrm{MPa}\right)$.

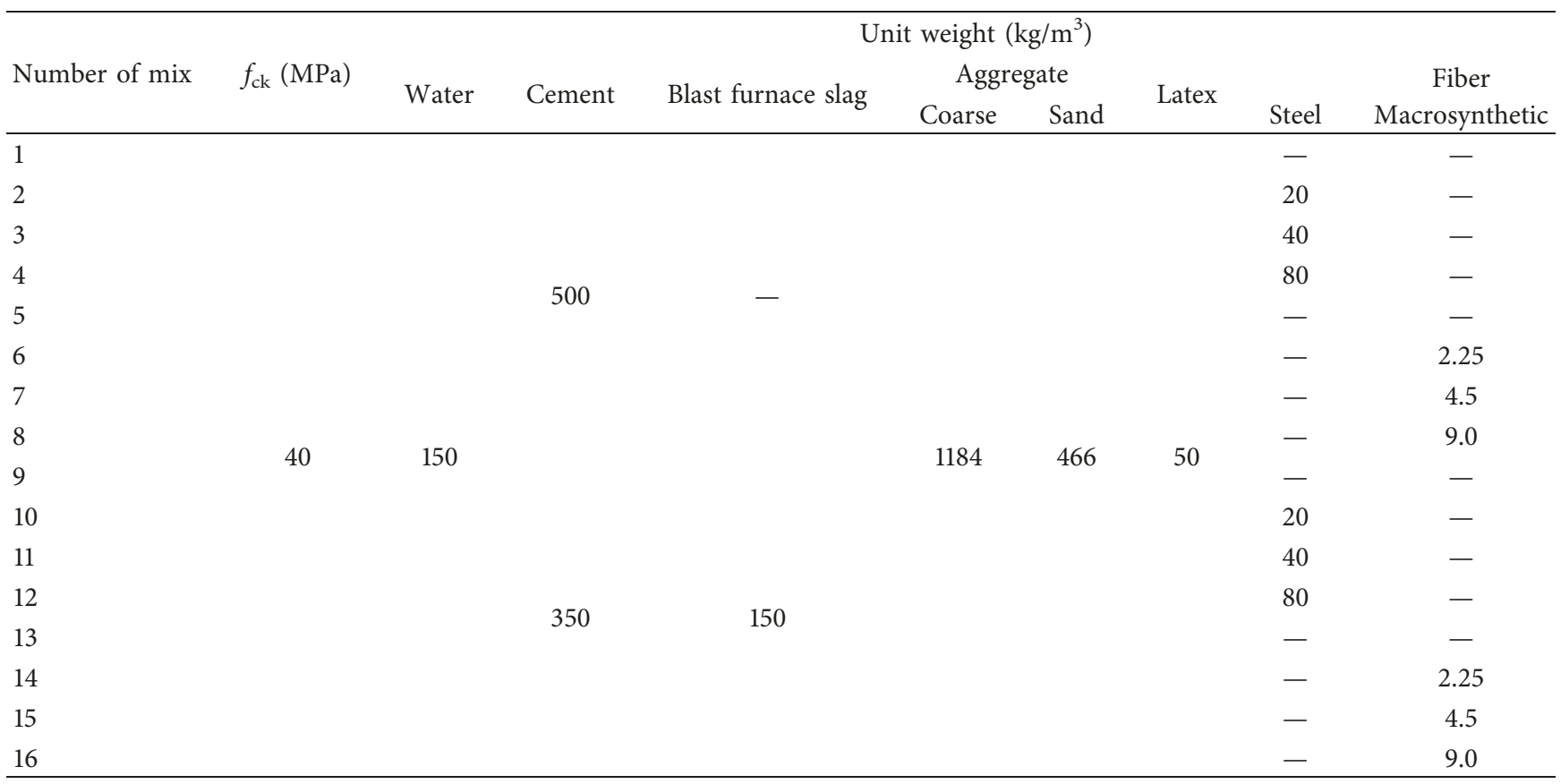

TABle 7: Mixture design of segment $\left(f_{\mathrm{ck}}=60 \mathrm{MPa}\right)$.

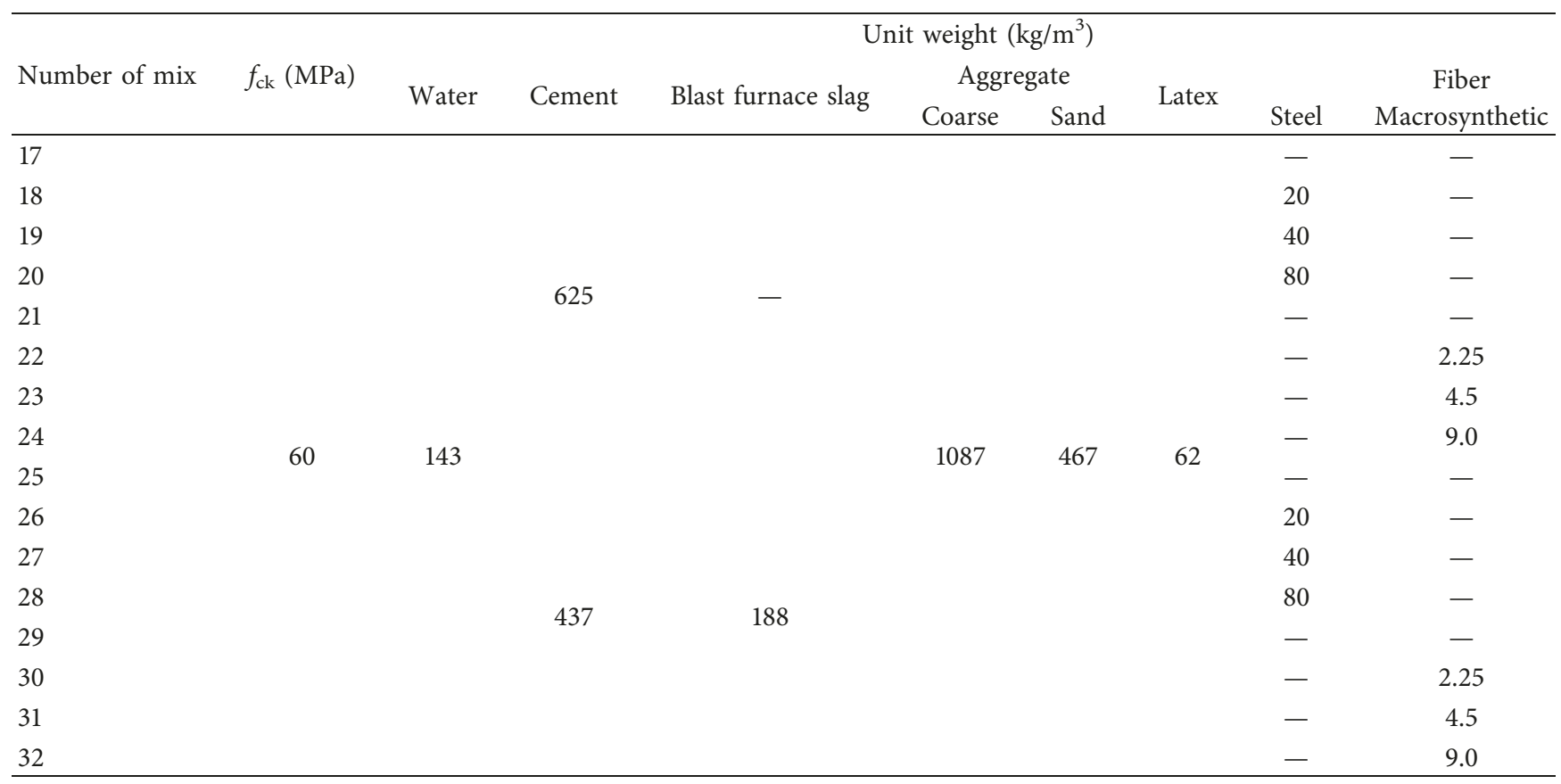




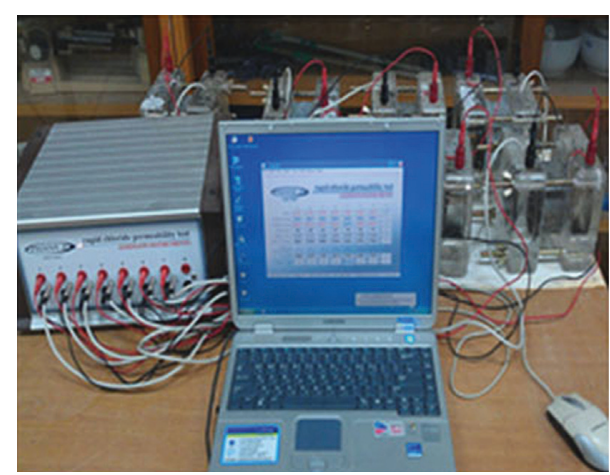

FIGURE 4: Chloride ion permeability setup.

TABLE 8: Standard of permeability levels by ASTM.

\begin{tabular}{lc}
\hline Charge passed (Coulombs) & Chloride permeability \\
\hline$>4000$ & High \\
$2000 \sim 4000$ & Moderate \\
$1000 \sim 2000$ & Low \\
$100 \sim 1000$ & Very low \\
$<100$ & Negligible \\
\hline
\end{tabular}

possible use of macrosynthetic fiber to replace the settle fiber as a mitigation measure to the steel fiber corrosion in the reinforced concrete structures. Concrete mixes containing steel fiber and macrosynthetic fiber showed similar compressive strength, regardless of volume fraction. The fiber type did not appear to affect the compressive strength, which indicated that the macrosynthetic fiber can replace the steel fiber.

The compressive strength increased as fiber volume fraction increased. Generally, concrete fluidity decreases with increasing fiber volume fraction due to poorer fiber dispersibility. This leads to a decrease in compressive strength. However, latex was added to the mixes to ensure fluidity, and the fiber was tempered for 2.5 minutes after the injection to increase its dispersibility. No compressive strength decrease was observed for the latex-added concrete mixes.

4.2. Flexural Strength. The flexural strength of concrete under a load is more critical than its compressive strength for a tunnel liner application. Figures 10-12 show the flexural strength results of the concrete with blast furnace slag. The blast furnace slag content increase in the mixes lowered the flexural strength of concrete; this was observed for the design strengths of 40 and $60 \mathrm{MPa}$, regardless of the fiber type or volume fraction. As a quasi-pozzolanic material, the fine particles delayed strength development. Consequently, flexural strength decreased.

The flexural strength increased with increasing fiber volume fraction. The effect of macrosynthetic fiber was slightly greater than that of steel fiber: the flexural strength was higher at a given volume fraction because the lower density of the macrosynthetic fiber indicated a higher number of fibers per unit volume. The flexural

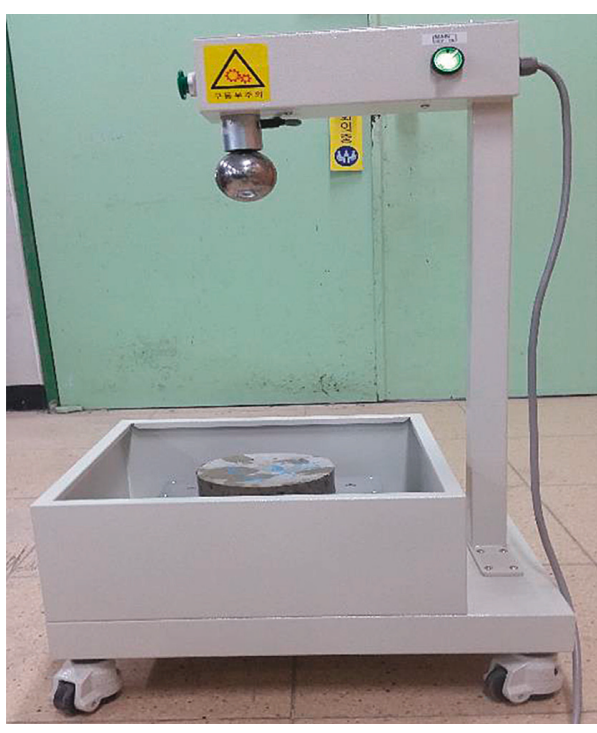

FIGURE 5: Impact resistance test setup.

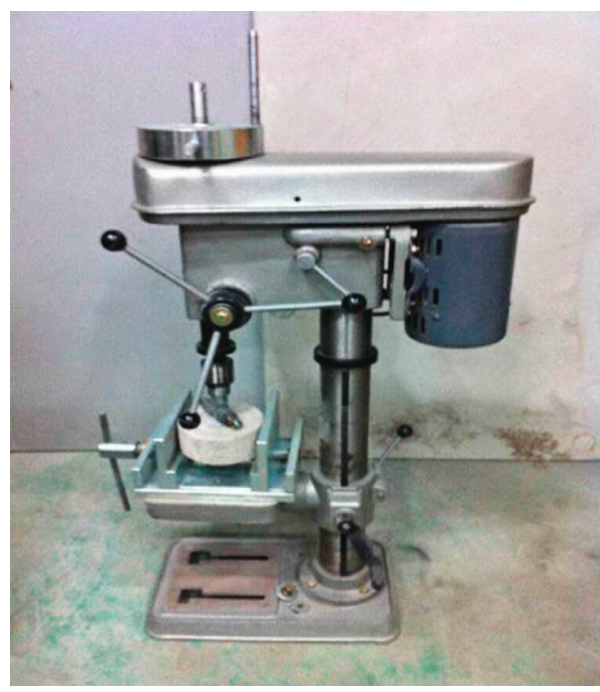

FIGURE 6: Abrasion test setup.

strength results showed that macrosynthetic fiber can replace steel fiber.

4.3. Chloride Ion Penetration. Figures 13-15 show the chloride ion penetration resistance results of the concrete containing reinforcing fiber and fine particles of blast furnace slag. The penetration decreased in those mixes containing fine particles of blast furnace slag because the fine particles filled the micropores of the concrete matrix.

The water permeability resistance increased with decreasing chloride ion penetration in the mixes containing macrosynthetic fiber, while the chloride ion penetration resistance improved with increasing fiber volume fraction. The high strength $(60 \mathrm{MPa})$ concrete mix containing the macrosynthetic fiber had the highest resistance, while 0.5 


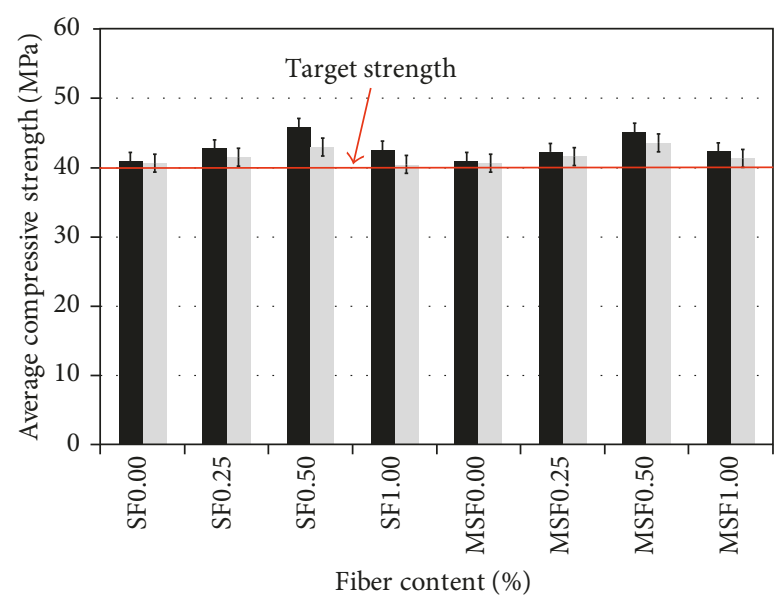

- $\mathrm{PC}$

$\because \mathrm{BSC}$

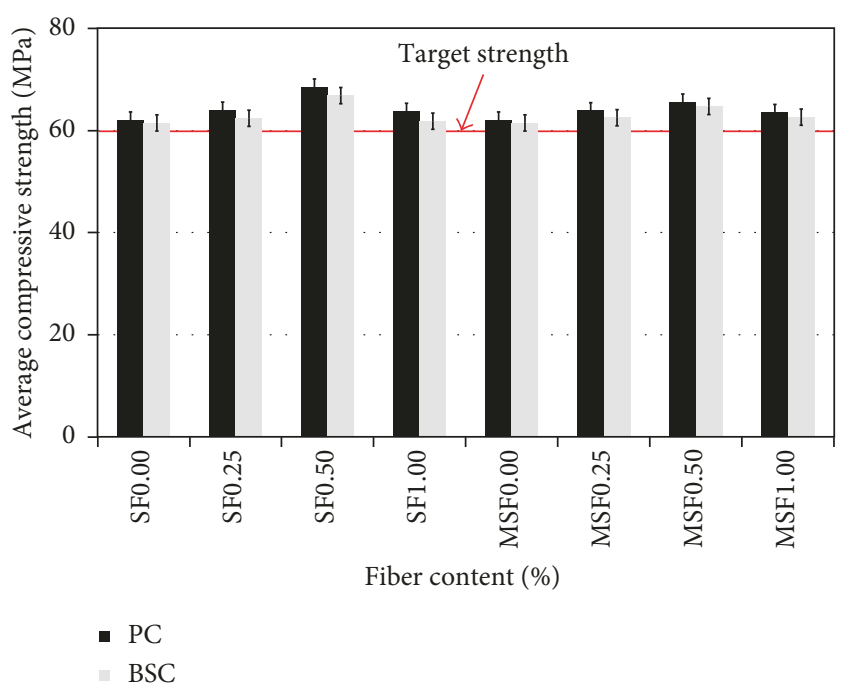

(b)

Figure 7: Compressive strength with fiber volume fraction. (a) Target strength $40 \mathrm{MPa}$. (b) Target strength $60 \mathrm{MPa}$.

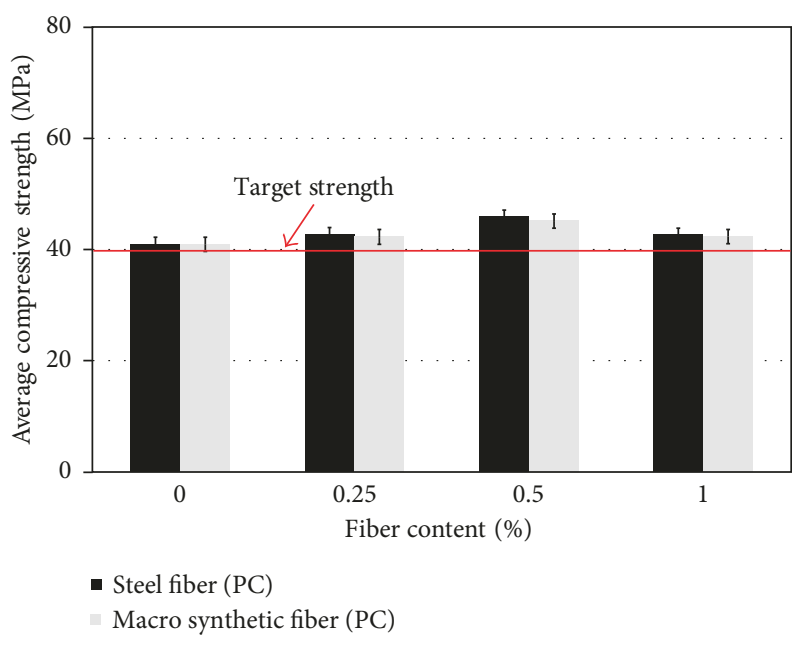

(a)

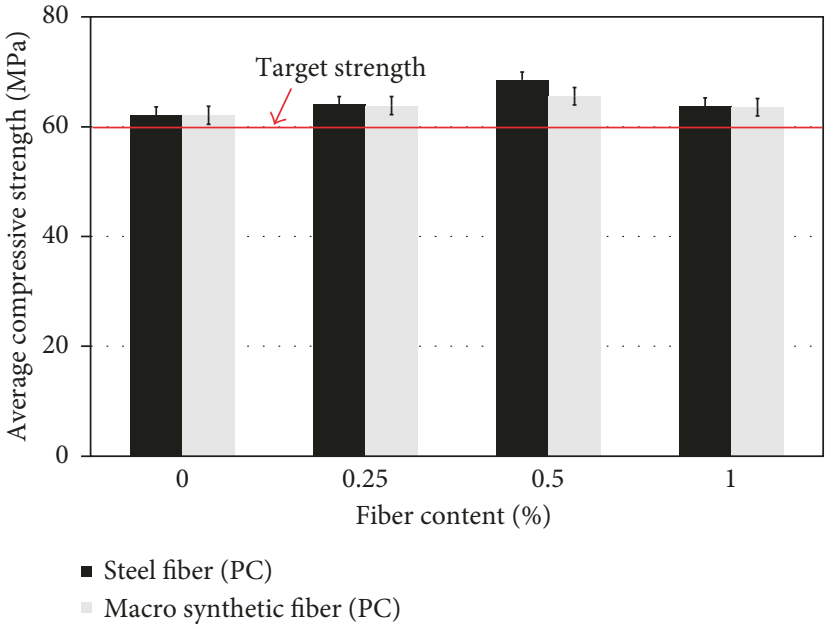

(b)

FIgURE 8: Compressive strength of PC segment with reinforcing fiber type. (a) Target strength $40 \mathrm{MPa}$. (b) Target strength $60 \mathrm{MPa}$.

and $1.0 \%$ volume fraction of the macrosynthetic fiber with fine particles of blast furnace slag resulted in a "very low" rating, according to the ASTM standard 1202. All other mixes scored "low" for the water permeability with an equal value throughout its range. Those $40 \mathrm{MPa}$ mixes containing macrosynthetic fiber all had "low" ratings, while the mixes with added steel fiber scored the "low" rating only at the 1.0\% substitution level. All the other mixes had "moderate" water permeability. Additionally, both steel fiber and macrosynthetic fiber mixes that also included fine particles of blast furnace slag had "low" water permeability. Macrosynthetic fiber performs better than steel fiber to enhance the water permeability resistance; other mixes that included fine particles of blast furnace slag also showed higher water permeability resistance.

\section{Determination and Performance of the Optimum Mix}

5.1. Determination of the Optimum Mix Proportions. The macrosynthetic fiber, steel fiber, and fine particles of blast furnace slag were used as variables to identify the optimum concrete mix design. The fine particles of blast furnace slag improved the chloride ion penetration resistance but reduced the initial compressive and flexural strengths. Nevertheless, all of the mixes met the design 


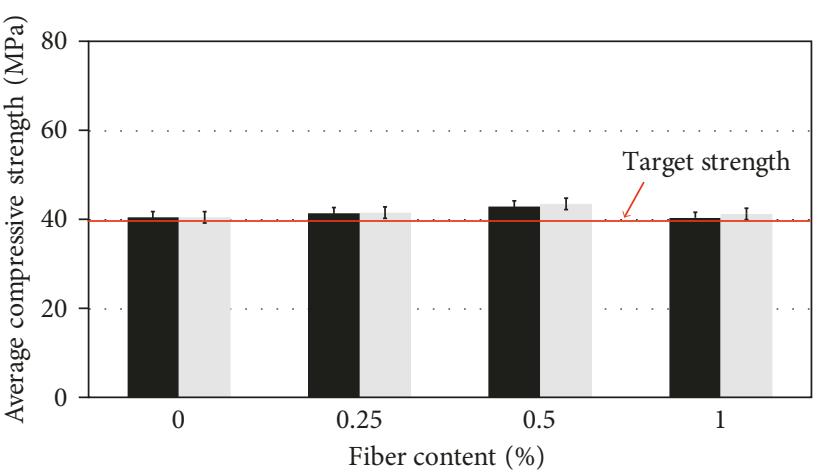

- Steel fiber (BSC)

Macrosynthetic fiber (BSC)

(a)

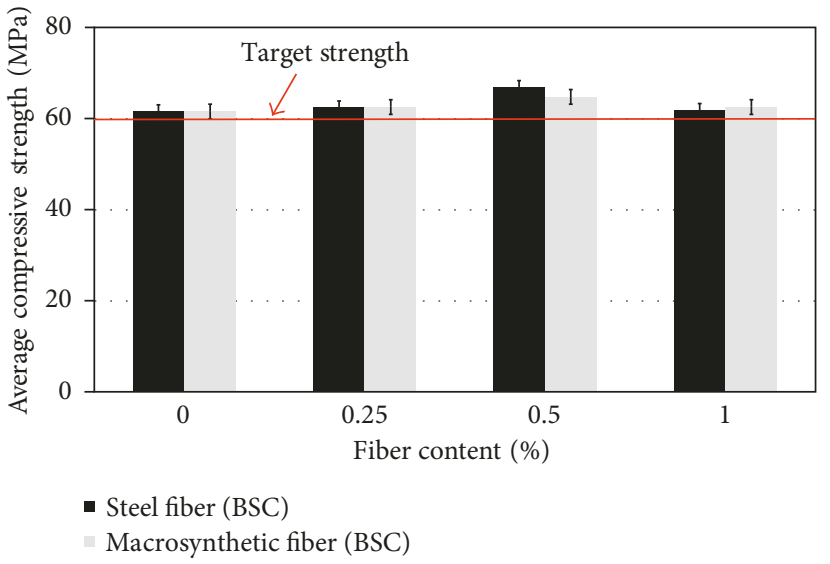

(b)

Figure 9: Compressive strength of BSC segment with reinforcing fiber type. (a) Target strength $40 \mathrm{MPa}$. (b) Target strength $60 \mathrm{MPa}$.

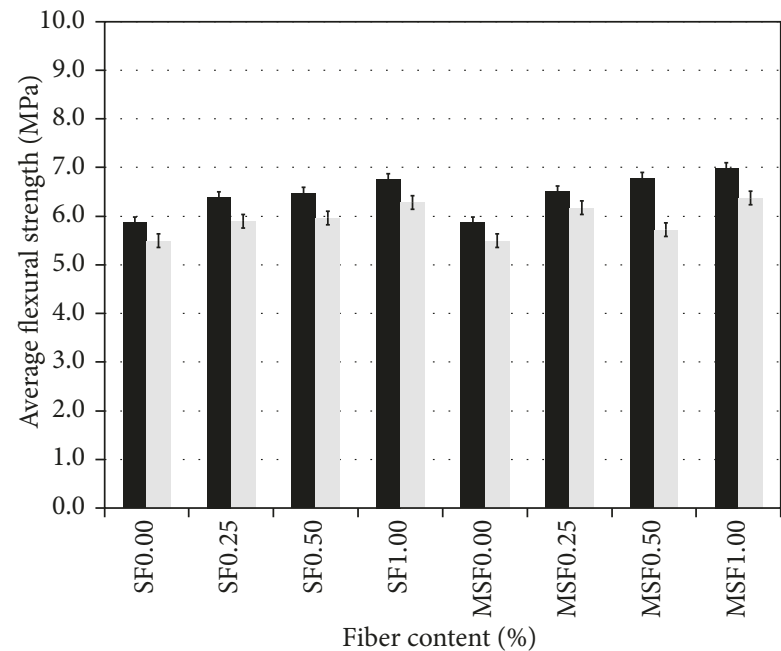

- $\mathrm{PC}$

BSC

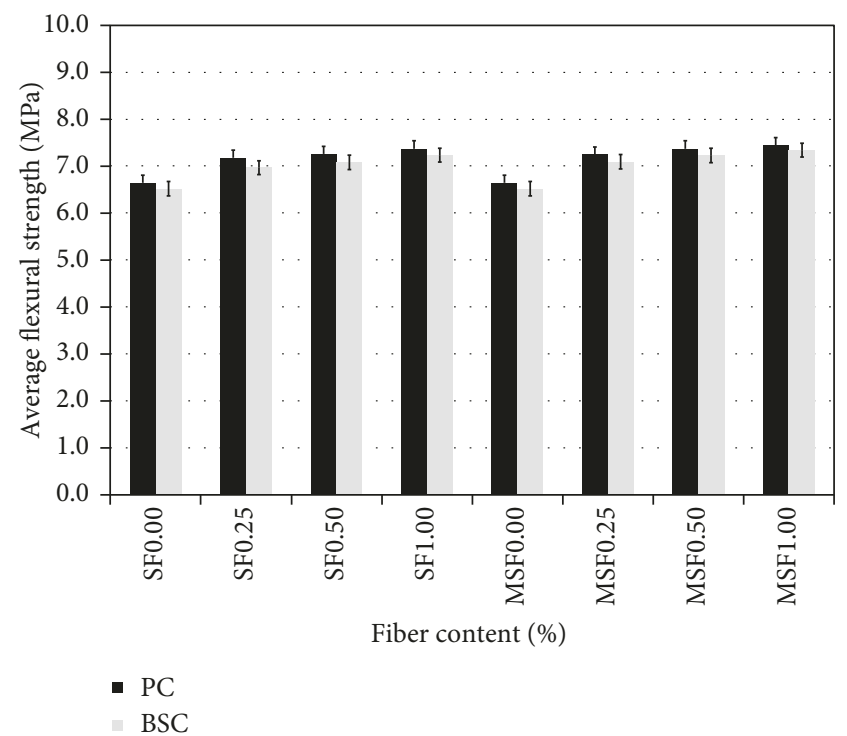

(b)

Figure 10: Flexural strength with fiber volume fraction. (a) Target strength $40 \mathrm{MPa}$. (b) Target strength $60 \mathrm{MPa}$.

strengths of 40 and $60 \mathrm{MPa}$. Hence, fine particles of blast furnace slag were added to all of the mixes. A steel fiber was not used for the optimum mix design determination due to its known corrosion issues. The properties of mixes containing $0.1 \%$ volume ratio of polypropylene fiber-added mix were measured, and this fiber addition prevented the formation of micro- and macrocracks. The mix proportions of the various tests were summarized in Table 9.

5.2. Evaluation of the Optimum Mix. This study compared and evaluated the mechanical properties and durability of the control mix (no reinforcing fiber) with the other mixes containing macrosynthetic fiber or hybrid fiber.
Figure 16 shows the test results for the compressive strength of the final optimum mix proportions. The mixes containing the hybrid fiber showed the highest strength, followed sequentially by those containing the macrosynthetic fiber and control fiber; the trends were the same for the 40 and $60 \mathrm{MPa}$ cases. Generally, mixing with reinforcing fiber affects the flexural strength to a greater degree than the compressive strength. It was also noted that the compressive strength did not increase significantly. All of the mixes achieved the 40 and $60 \mathrm{MPa}$ design strengths.

Figure 17 shows the flexural strength results for the optimum mix. The mix containing the hybrid fiber had the 


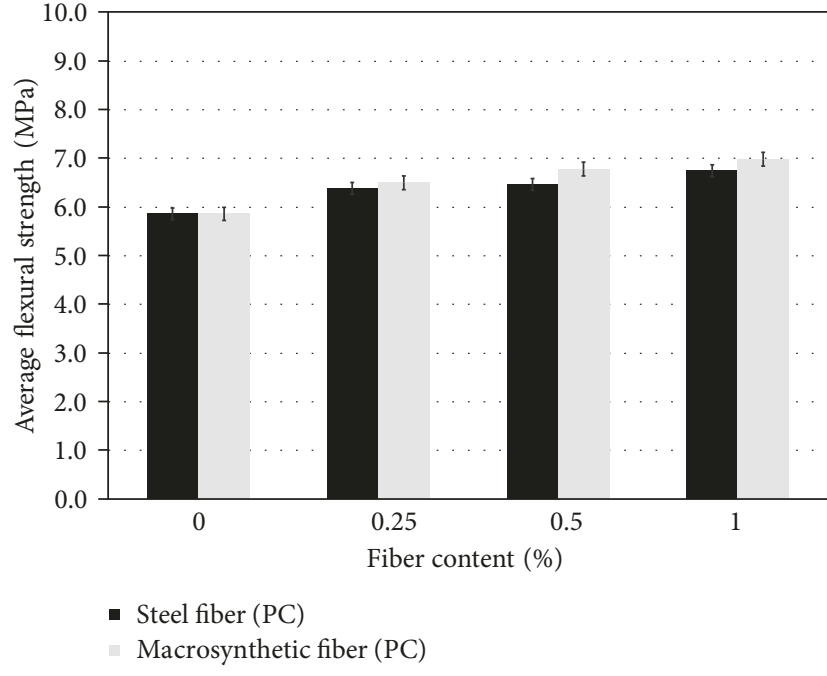

(a)

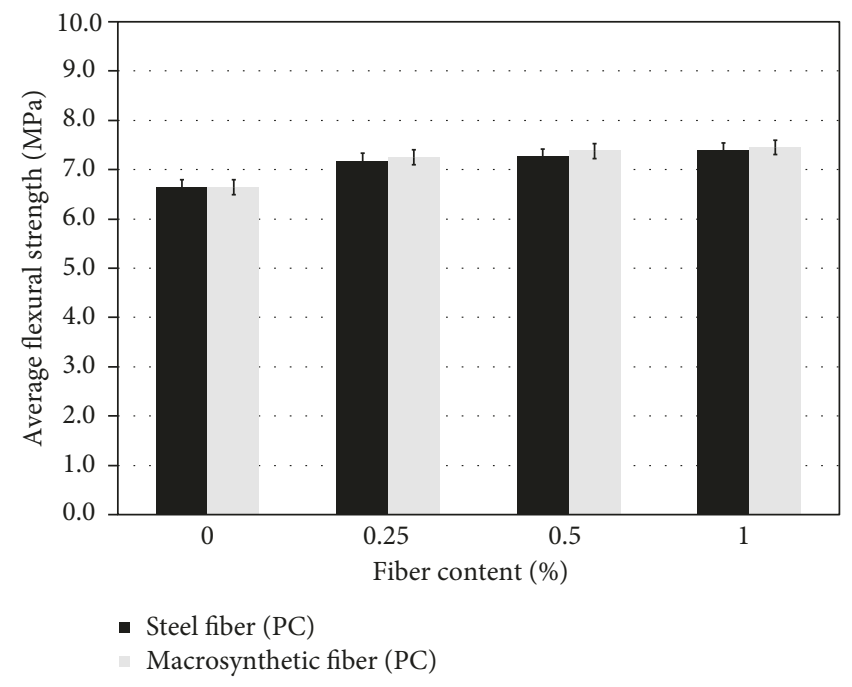

(b)

Figure 11: Flexural strength of PC segments with reinforcing types. (a) Target strength $40 \mathrm{MPa}$. (b) Target strength $60 \mathrm{MPa}$.

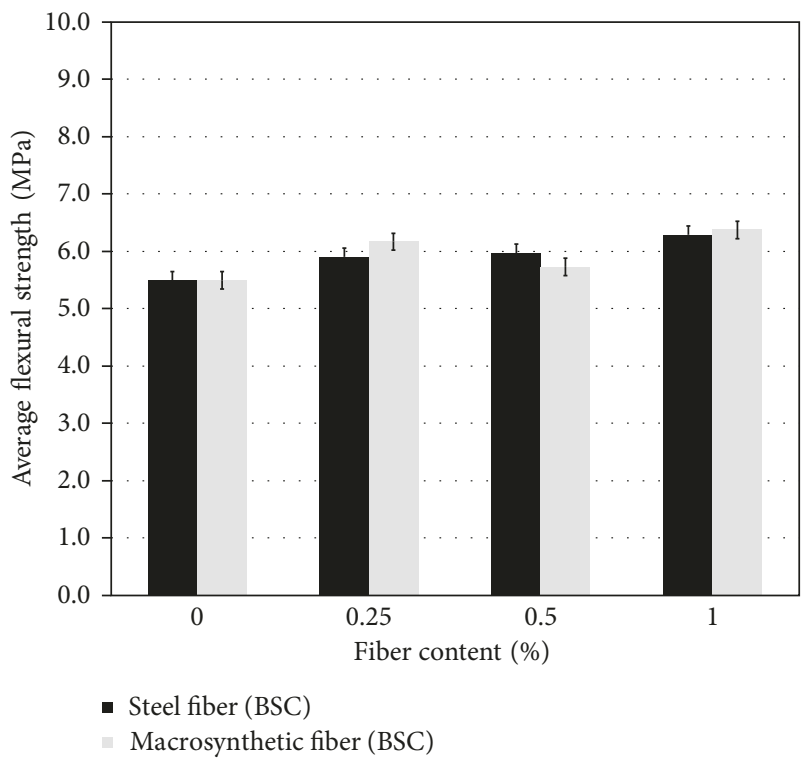

(a)

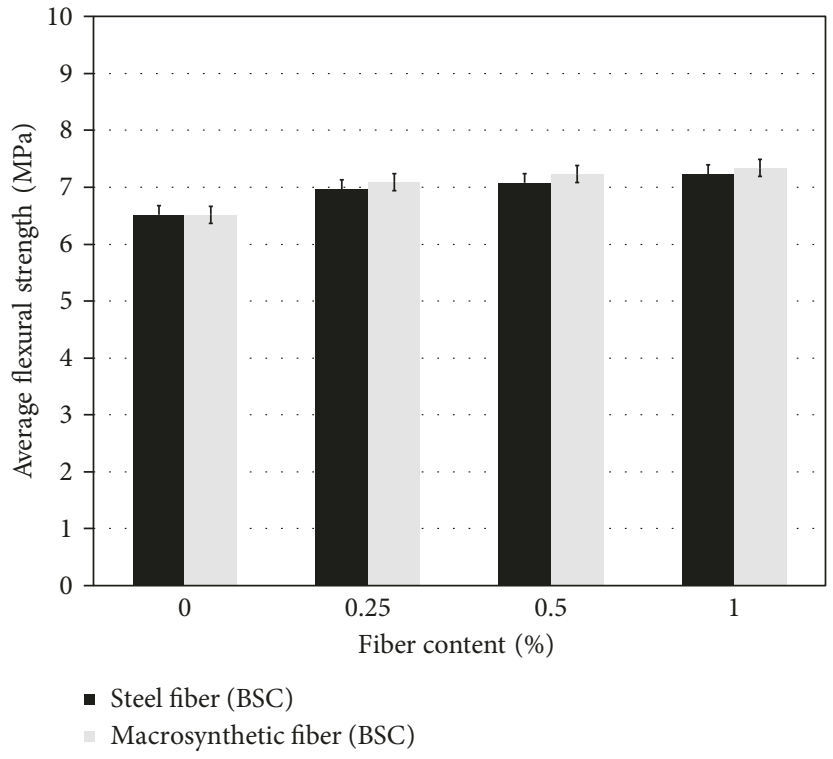

(b)

Figure 12: Flexural strength of BSC segments with reinforcing types. (a) Target strength $40 \mathrm{MPa}$. (b) Target strength $60 \mathrm{MPa}$.

highest flexural strength, followed by the macrosynthetic fiber and control mixes. This was because the hybrid fiber mix used a blend of macrosynthetic and polypropylene fibers to effectively control micro- and macrocrack formation in the concrete. The macrosynthetic fiber mix also had a higher flexural strength than the control mix and also controlled crack formation more effectively than the control mix.

Figure 18 shows the chlorine ion penetration results for the final mix composition. The mix containing the hybrid fiber had the lowest penetration, followed by that containing the macrosynthetic fiber and the control. For the designed $40 \mathrm{MPa}$ mixes, the control mix with its value greater than $2000 \mathrm{C}$ indicated moderate permeability, while the macrosynthetic fiber and hybrid fiber mixes had low permeability and very low permeability, respectively. For the designed $60 \mathrm{MPa}$ mixes, the control mix had a low water permeability (1500 C or higher) while the addition of macrosynthetic or hybrid fibers provided very low water permeability. The permeability resistance of latex-modified segment concrete was increased by adding reinforcing fibers. Also, mixes with hybrid fiber had a better permeability resistance than the mix with the macrosynthetic fiber, because the presence of polypropylene fiber controls the crack formation. 


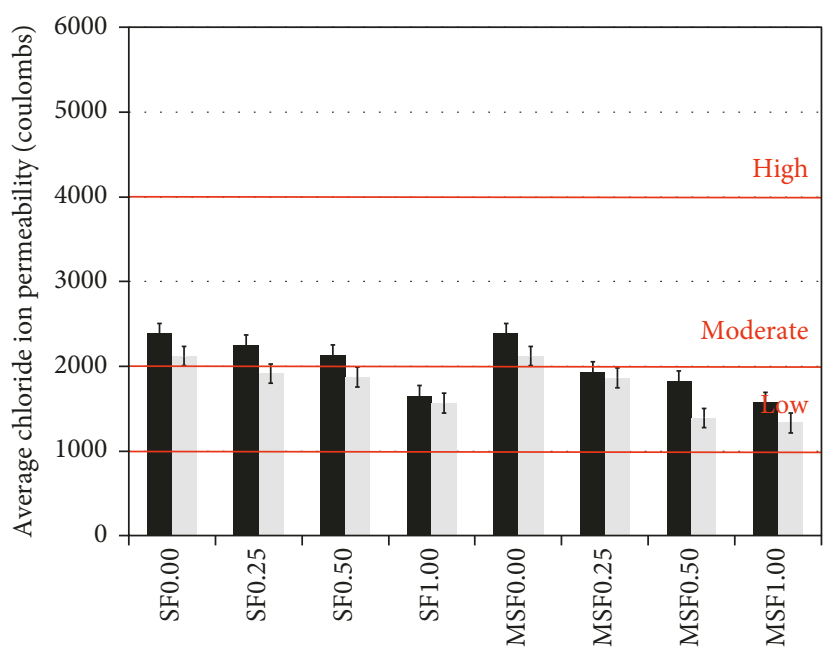

Fiber content (\%)

- $\mathrm{PC}$

BSC

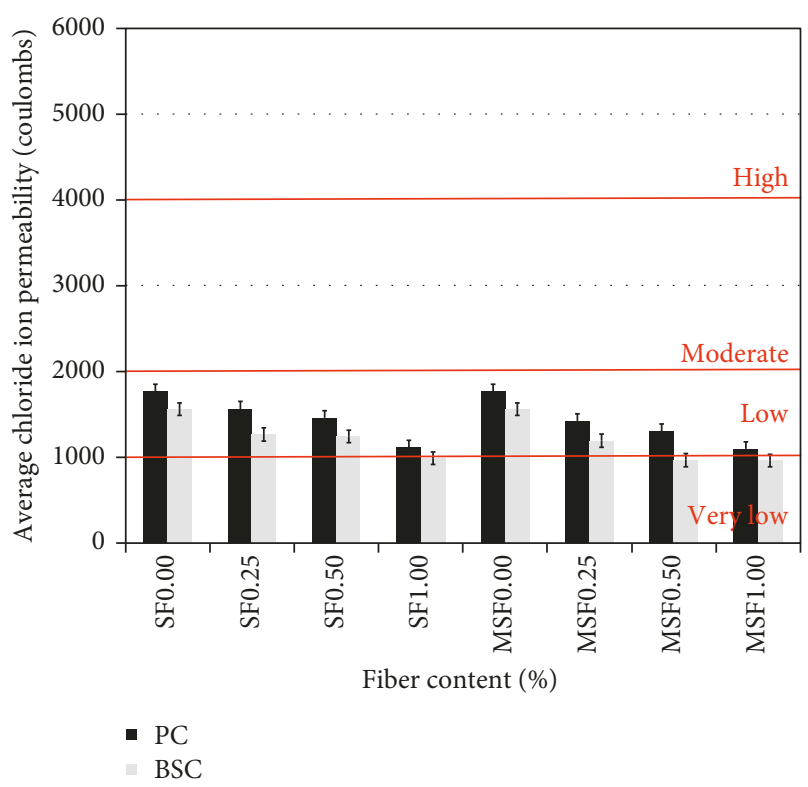

(b)

FiguRE 13: Chloride ion penetration test results of concrete segments with fiber volume fraction. (a) $40 \mathrm{MPa}$. (b) $60 \mathrm{MPa}$.

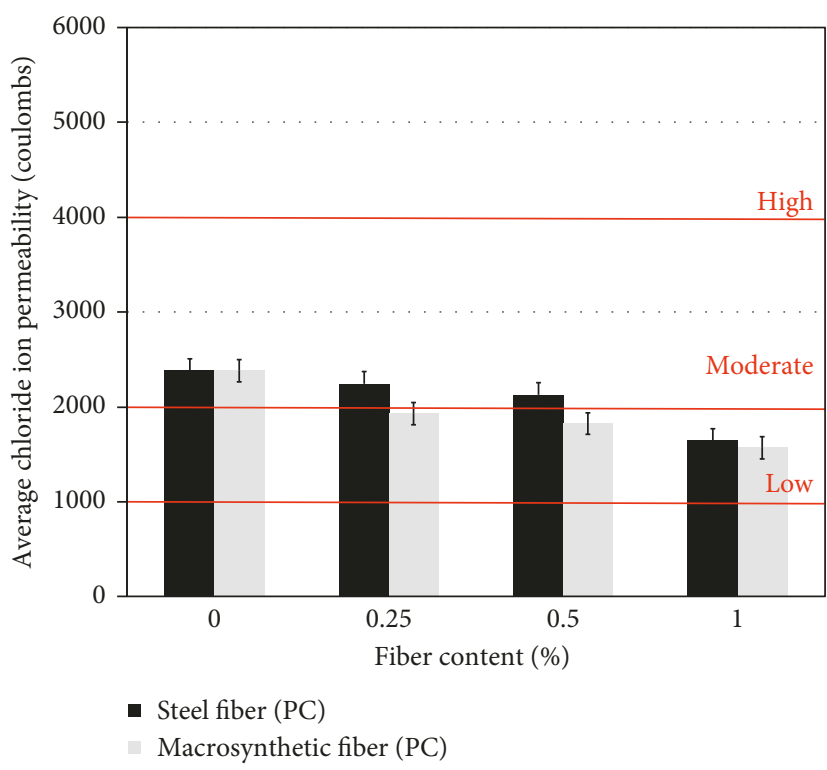

(a)

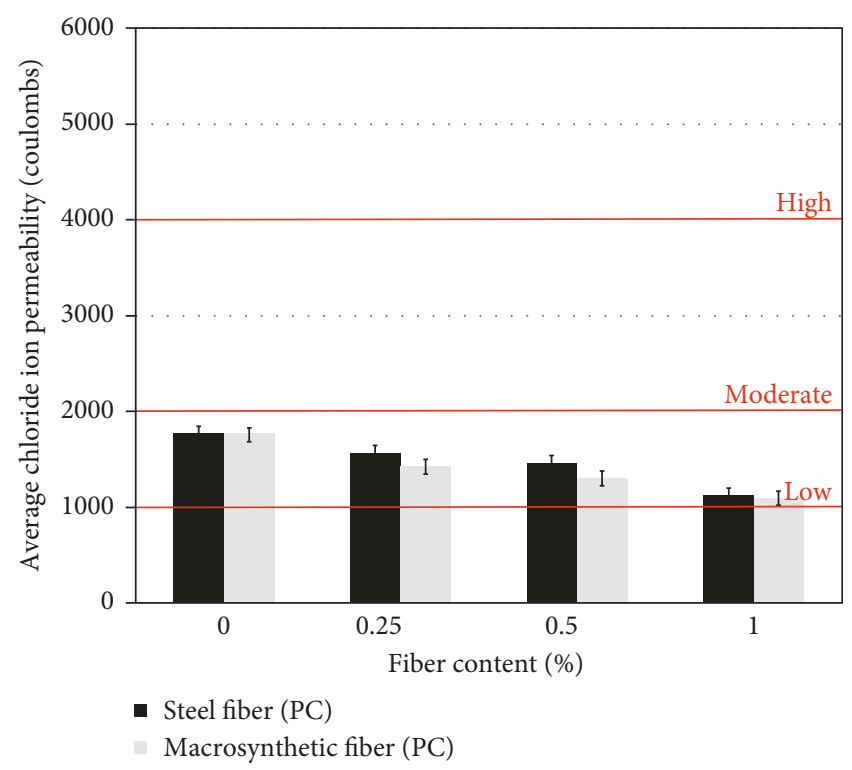

(b)

FIGURE 14: Chloride ion penetration of PC segments with reinforcing types. (a) $40 \mathrm{MPa}$. (b) $60 \mathrm{MPa}$.

Figure 19 shows the impact resistance results of the optimum mix. The improvement followed the order of control mix $<$ macrosynthetic fiber mix $<$ hybrid fiber mix, because adding a reinforcing fiber helped to absorb the impact. A fiber reinforcement of concrete improves flexural toughness and energy absorption capacity through complex steps of pullout, debonding, bridging, and fracture and consequently, increases impact resistance. Therefore, mixes with macrosynthetic fiber had better impact resistance than those lacking reinforcing fiber. Moreover, using the hybrid blend of macrosynthetic fiber with polypropylene fiber suppressed the formation of micro- and macrocracks, thereby increasing the energy absorbing capacity and impact resistance. Figure 20 has photographs of impact test specimens after the test. The optimum mix containing fiber only got the microcracks. Mixes lacking reinforcing fiber displayed microcracks in the $40 \mathrm{MPa}$ design case but macrocracks in the $60 \mathrm{MPa}$ 


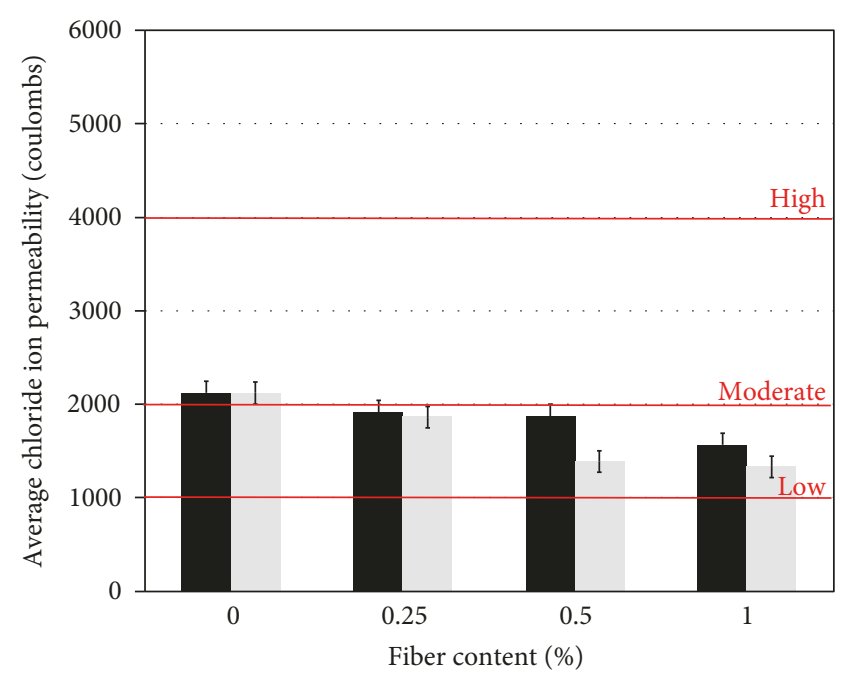

- Steel fiber (PC)

Macrosynthetic fiber (PC)

(a)

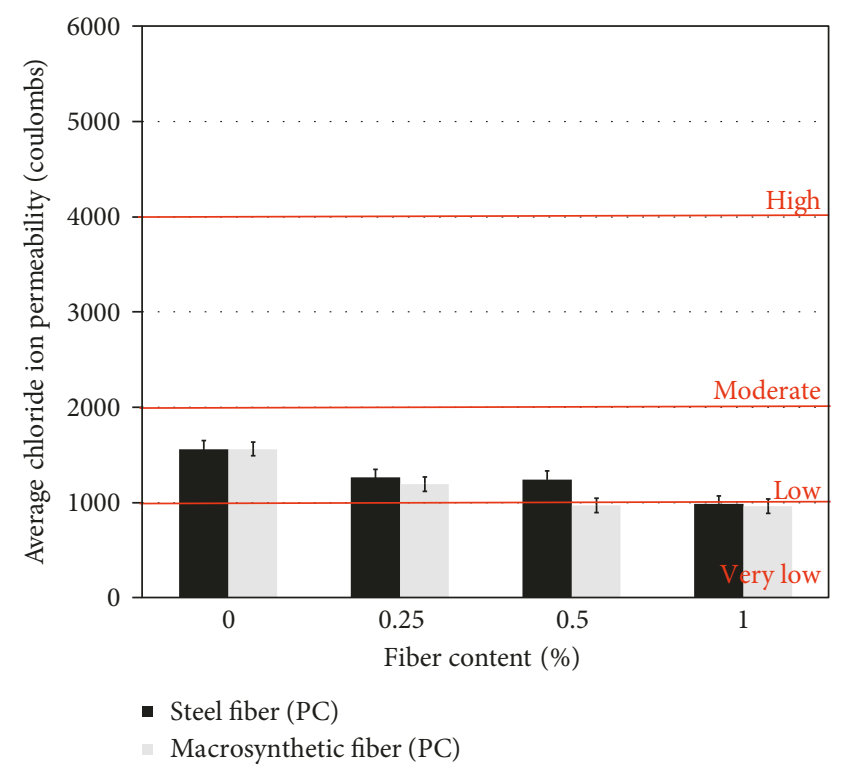

(b)

FIgURE 15: Chloride ion penetrations of BSC segments with reinforcing types. (a) $40 \mathrm{MPa}$. (b) $60 \mathrm{MPa}$.

TABLE 9: Mixing ratio for optimum mix proportions determination.

\begin{tabular}{|c|c|c|c|c|c|c|c|c|c|}
\hline \multirow{2}{*}{ Design strength $(\mathrm{MPa})$} & \multirow{2}{*}{ Type of mix } & \multicolumn{8}{|c|}{ Unit weight $\left(\mathrm{kg} / \mathrm{m}^{3}\right)$} \\
\hline & & $W$ & $C$ & BFS & $G$ & $S$ & Latex & Macrosynthetic fiber & Polypropylene fiber \\
\hline 40 & $\begin{array}{c}\text { Control } \\
\text { Macrosynthetic fiber } \\
\text { Hybrid fiber }\end{array}$ & 150 & 350 & 150 & 1184 & 466 & 50 & $\begin{array}{l}- \\
9 \\
9\end{array}$ & $\overline{-}$ \\
\hline 60 & $\begin{array}{c}\text { Control } \\
\text { Macrosynthetic fiber } \\
\text { Hybrid fiber }\end{array}$ & 143 & 437 & 188 & 1087 & 467 & 62 & $\begin{array}{l}- \\
9 \\
9\end{array}$ & $\frac{-}{0.9}$ \\
\hline
\end{tabular}

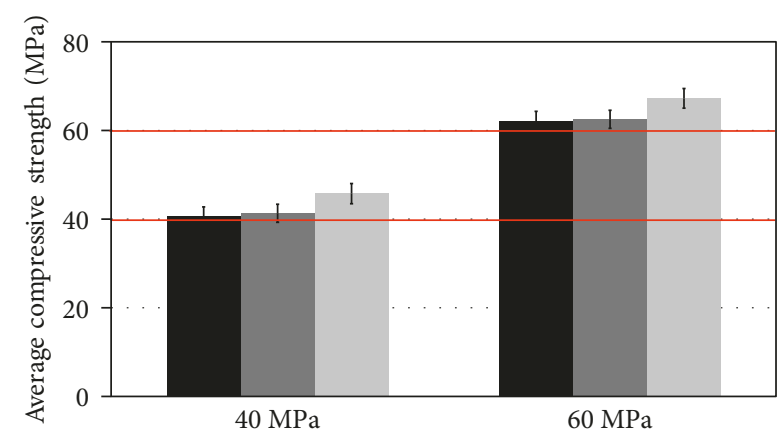

Type of design strength

- Control

- Macrosynthetic fiber

- Hybrid fiber

FIgURE 16: Compressive strength of optimum mix ratio.

design case. The higher strength was accompanied by increased brittleness, leading to macrocracks and ultimately failure. However, stronger specimens require

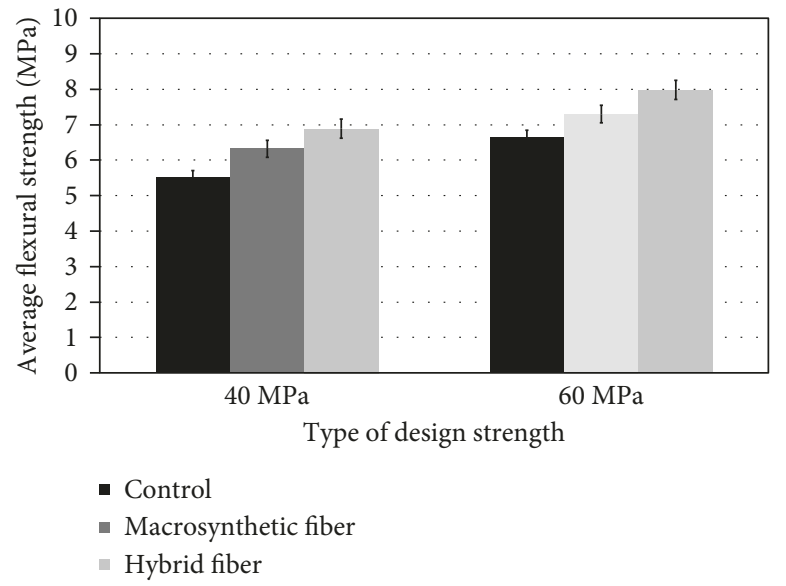

FIGURE 17: Flexural strength of optimum mix ratio.

higher numbers of impacts until failure; the crack width and number of impacts were accordingly higher for the $60 \mathrm{MPa}$ design mixes in this study. 


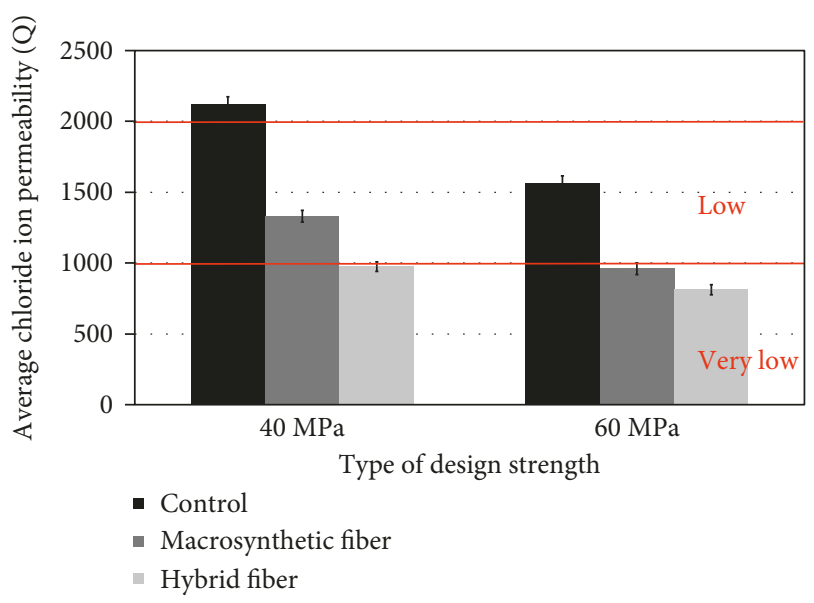

Figure 18: Chloride ion penetration of optimum mix ratio.

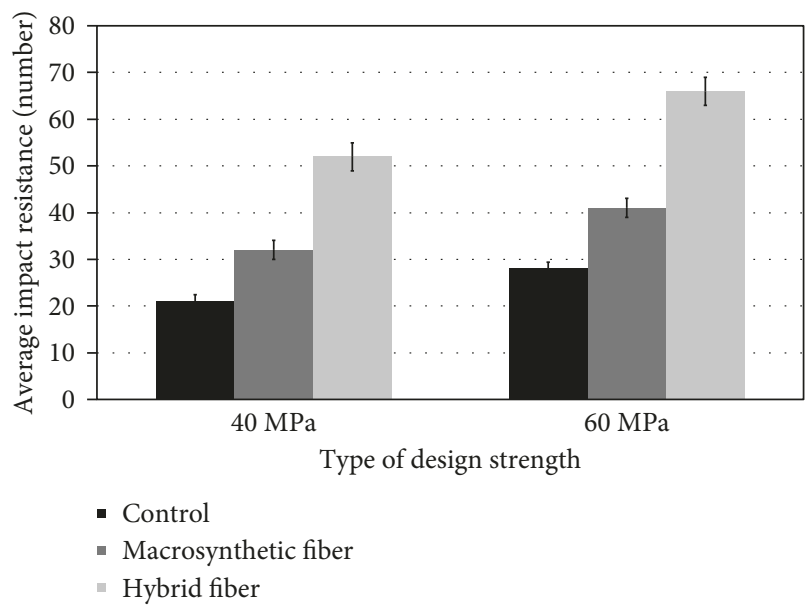

FIGURE 19: Impact resistance of optimum mix ratio.

Figure 21 shows the abrasion resistance results for the optimum mix. The resistance improved in the order of control mix $<$ macrosynthetic fiber mix $<$ hybrid mix. The hybrid mix comprising a blend of macrosynthetic fiber and polypropylene fiber increased the abrasion resistance through a crosslinking effect as the fiber resisted separation of concrete powder and pieces during the abrasion process. Notably, for the hybrid mix, macrocracks created on the normal concrete surface by abrasion were controlled by the macrosynthetic fiber, while microcracks were mitigated by the polypropylene fiber, providing an overall improvement in abrasion resistance. Figure 22 shows the specimens after the abrasion test. Surface abrasion was less for the mixes containing macrosynthetic and hybrid fibers than the control mix.

As a result of evaluating the mechanical performance and durability of the optimum mix according to the type of fiber, the hybrid fiber application showed the best performance. Generally, hybrid fiber is effective to suppress microcrack and macrocrack simultaneously in concrete [12]. A microfiber of small length and diameter inhibits the generation and growth of microcracks. Macrofiber with a large length and diameter

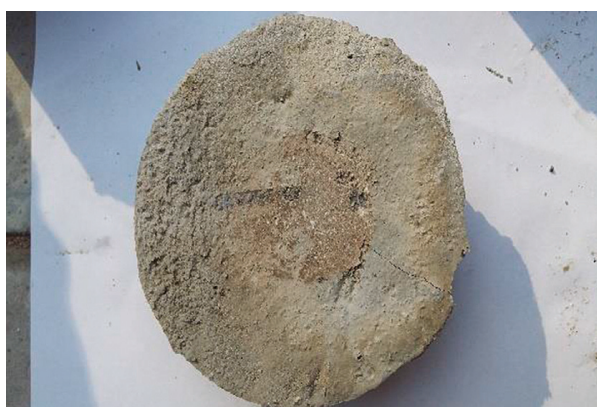

(a)

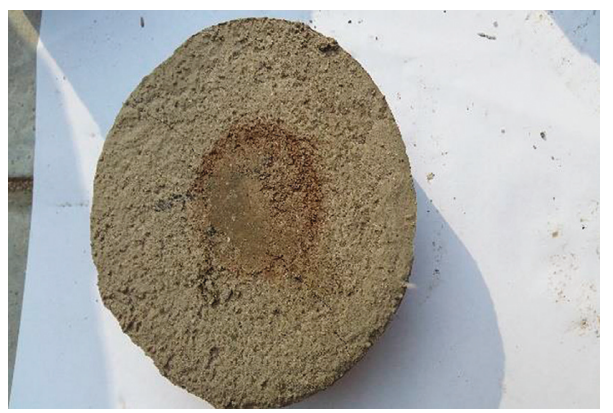

(b)

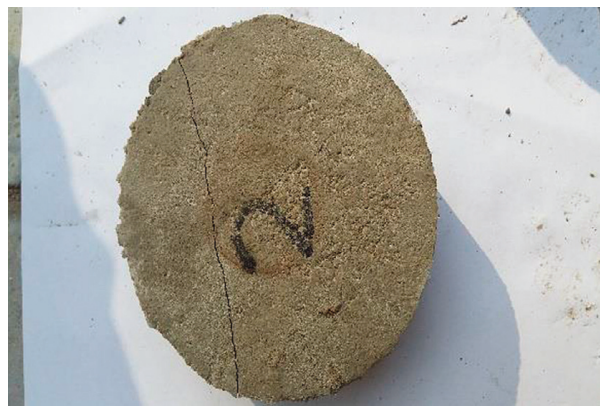

(c)

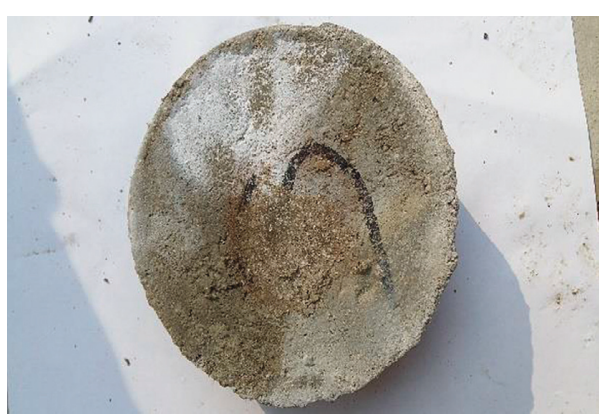

(d)

Figure 20: Photographs of fracture shape after impact test. (a) $40 \mathrm{MPa}$ (control). (b) $40 \mathrm{MPa}$ (optimum). (c) $60 \mathrm{MPa}$ (control). (d) $60 \mathrm{MPa}$ (optimum).

inhibits the initiation and growth of microcracks. Therefore, the addition of hybrid fibers to concrete improves the mechanical performance and durability of concrete by simultaneously controlling microcracks and macrocracks. In this study, polypropylene fibers were used for fibers of small length and diameter (microfiber), and macrosynthetic fibers were applied for fibers of long length and diameter 


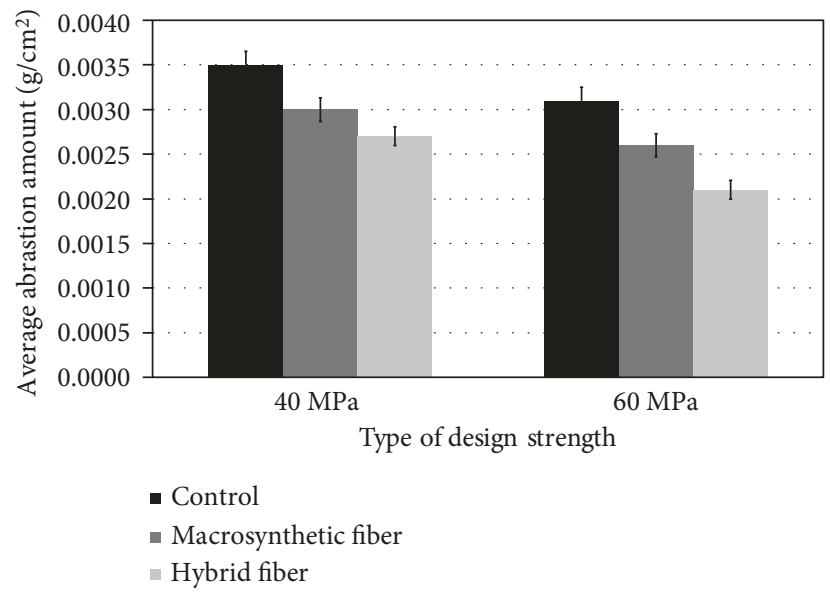

Figure 21: Abrasion resistance of optimum mix ratio.

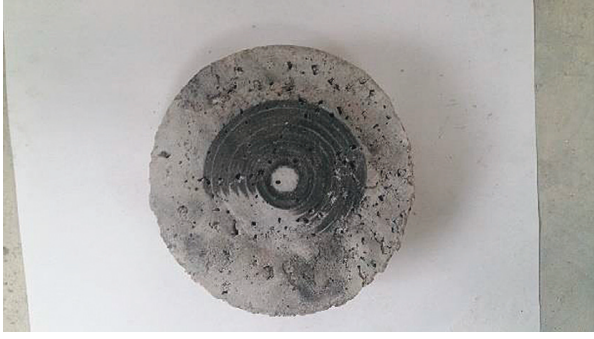

(a)

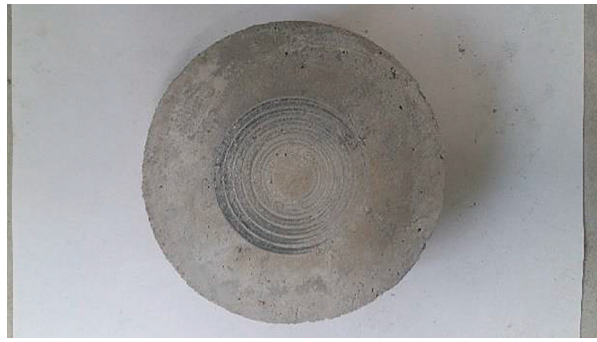

(c)

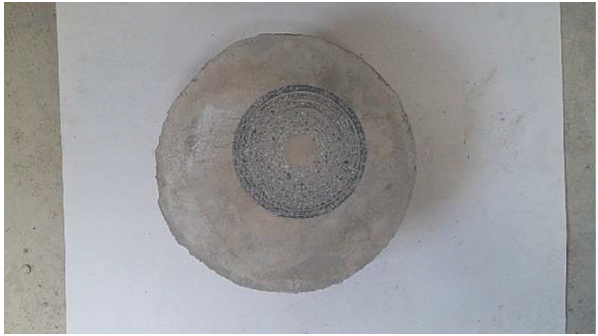

(b)

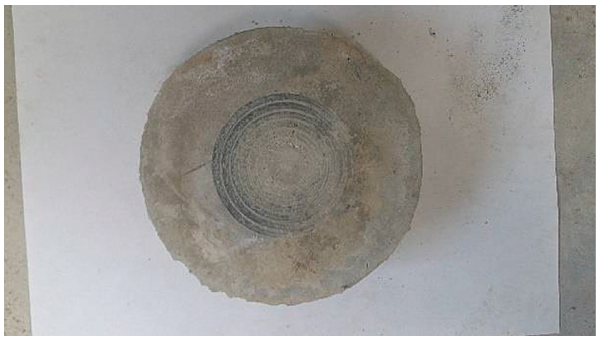

(d)

Figure 22: Photo of abrasion specimens after abrasion. (a) $40 \mathrm{MPa}$ (control). (b) $40 \mathrm{MPa}$ (optimum). (d) $60 \mathrm{MPa}$ (control). (d) $60 \mathrm{MPa}$ (optimum).

(macrofiber). Therefore, mechanical properties (compressive strength and bending strength), permeability, impact resistance, and abrasion resistance were improved compared to concrete without macrosynthetic fiber and concrete without fiber. That is, polypropylene fiber was added to concrete to suppress the generation and growth of microcracks, and macrosynthetic fiber to suppress macrocracks, thereby improving concrete performance.

\section{Conclusions}

This study evaluated the mechanical properties and durability of latex-modified fiber-reinforced concrete as an alternative to conventional steel fiber-reinforced concrete. Macrosynthetic, steel, and hybrid (macrosynthetic + polypropylene) fibers were used as reinforcing fibers. The results of the study are summarized as follows:

(1) Adding fine particles of blast furnace slag decreased the compressive strength. The effect of reinforcing fiber and fiber volume fraction were not significant. All mixes achieved the design strengths of 40 and $60 \mathrm{MPa}$.

(2) Adding fine particles of blast furnace slag decreased flexural strength. However, the strength increased with increasing volume fraction of reinforced fiber. Macrosynthetic fiber provided a slightly better flexural strength than steel fiber.

(3) Adding fine particles of blast furnace slag decreased the chloride ion penetration, which indicated improved water permeability resistance. Chloride ion 
penetration decreased with increasing fiber volume fraction. Macrosynthetic fiber provided a better water permeability resistance than did steel fiber.

(4) The compressive strength, flexural strength, and chloride ion penetration resistance results were used to obtain the optimum mix composition. The optimum mix contained fine particles of blast furnace slag and macrosynthetic fiber.

(5) The mechanical durability was assessed for the optimum mix by varying the reinforcing fiber type, that is, no reinforcing fiber (control), macrosynthetic fiber, and hybrid fiber (macrosynthetic fiber + polypropylene fiber). The compressive strength, flexural strength, chloride ion water permeability test, impact resistance, and abrasion resistance are followed in the order of the control mix $<$ macrosynthetic fiber mix $<$ hybrid fiber mix.

(6) The addition of hybrid fiber effectively controlled the formation of macro- and microcracks.

(7) Macrosynthetic fiber is also a feasible replacement for steel fiber in the latex-modified concrete.

\section{Conflicts of Interest}

The authors declare that they have no conflicts of interest.

\section{Acknowledgments}

This research was supported by a grant (15SCIP-B105148-01) from the Construction Technology Research Program funded by the Ministry of Land, Infrastructure, and Transport of the Korean Government.

\section{References}

[1] S. J. You and C. S. You, "A study on the member forces of segmental linings considering key segments," Journal of Korean Tunnelling and Underground Space Association, vol. 17, no. 3, pp. 363-382, 2015.

[2] S. H. Chang, G. P. Lee, S. W. Choi, and G. J. Bae, "State of the art of segment lining in shield tunnel and statistical analysis of its key design parameters," Journal of the Korean Society for Rock Mechanics, vol. 21, pp. 427-438, 2011.

[3] W. G. Lee, H. I. Kim, B. C. Jung, J. I. Kim, and H. Woo, “A construction plan of double shield TBM in steep tunnel and fault zone," Korean Tunelling and Underground Space Association, vol. 21, pp. 427-438, 2008.

[4] C. S. You and H. M. A. Jeon, "Comparative study on methods for shield tunnel segment lining sectional forces," Korean Tunelling and Underground Space Association, vol. 14, pp. 159-181, 2012.

[5] G. Tiberti, G. A. Plizzari, J. C. Walraven, and C. B. M. Blom, Concrete Tunnel Segments with Combined Traditional and Fiber Reinforcement, Taylor \& Francis Group, London, UK, ISBN 978-0-415-47535-8, 2008.

[6] S. Abbas, Structural and Durability Performance of Precast Segmental Tunnel Linings, University of Western Ontario, London, ON, Canada, 2014.

[7] J. P. Won, C. G. Park, Y. J. Kim, and K. H. Park, "Bond properties of synthetic and steel single fiber in high strength cement based composites," Journal of the Korean Society for Civil Engineers, vol. 27, pp. 609-616, 2007.

[8] J. P. Won, C. G. Park, Y. J. Kim, and C. W. Lee, "Pullout behavior of polyolefin synthetic fibers with hydrophilic surface treatment in cement matrix," Journal of the Korean Society for Civil Engineers, vol. 27, pp. 453-460, 2007.

[9] N. Banthia, P. Gupta, C. Yan, and D. R. Morgan, "How tough is fiber reinforced shotcrete? Part 1. Beam tests," Concrete International, vol. 21, pp. 59-62, 1999.

[10] N. Banthia, P. Gupta, C. Yan, and D. R. Morgan, "How tough is fiber reinforced shotcrete? Part 2. Plate tests," Concrete International, vol. 21, pp. 62-69, 1999.

[11] R. Chris, M. Kyran, and J. S. Pei, Fiber-Reinforced Concrete and Bridge Deck Cracking, University of Oklahoma Graduate College, Norman, OK, USA, 2006.

[12] J. H. Lee and C. G. Park, "Effect of natural jute fiber on bond between polyolefin based macro fiber and cement matrix," Journal of the Korean Society for Civil Engineers, vol. 31, pp. 251-260, 2011.

[13] H. B. Wagner and D. G. Grenley, "Interphase effects in polymer-modified hydraulic cements," Journal of Applied Polymer Science, vol. 22, no. 3, pp. 813-822, 1978.

[14] Y. Ohama, "Study on properties and mix proportioning of polymer-modified mortars for buildings," in Report of the Building Research Institute, p. 65, Building Research Institute, Tokyo, Japan, 1973.

[15] H. W. Song, S. J. Kwon, S. W. Lee, and K. J. Byun, "A study on resistance of chloride ion penetration in ground granulated blast-furnace slag concrete," Journal of the Korea Concrete Institute, vol. 15, pp. 400-408, 2003.

[16] D. Hester, C. Mcnally, and M. G. Richardson, "Study of influence of slag alkali level on the alkali-silica reactivity of slag concrete," Construction and Building Materials, vol. 19, no. 9, pp. 661-665, 2005.

[17] F. Leng, N. Feng, and X. Lu, "An experiment study on the properties of resistance to diffusion of chloride ions of fly ash and blast furnace slag concrete," Cement and Concrete Research, vol. 30, no. 6, pp. 989-992, 2000.

[18] American Concrete Institute, Guide for the Use of Polymers in Concrete, ACI Committee 548, Detroit, MI, USA, 1997.

[19] ASTM C39, Standard Test Method for Compressive Strength of Cylindrical Concrete Specimens, American Society for Testing and Materials, Philadelphia, PA, USA, 2015.

[20] ASTM C 78/C78M, Standard Test Method for Flexural Strength of Concrete (Using Simple Beam with Third-Point Loading), American Society for Testing and Materials, Philadelphia, PA, USA, 2015.

[21] ASTM C 1202-94, Standard Test Method for Electrical Indication of Concrete's Ability to Resist Chloride Ion Penetration, American Society for Testing and Materials, Philadelphia, PA, USA, 1997.

[22] American Concrete Institute, State-of-the-Art Report on Fiber Reinforced Concrete, ACI Committee 544, Detroit, MI, USA, 2002.

[23] ASTM C 944, Standard Test Method for Abrasion Resistance of Concrete or Mortar Surfaces by the Rotating-Cutter Method, American Society for Testing and Materials, 2005. 


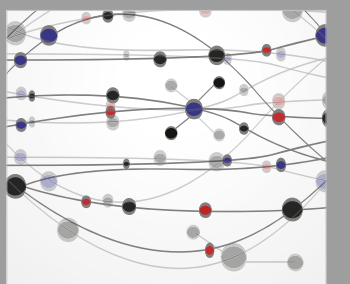

The Scientific World Journal
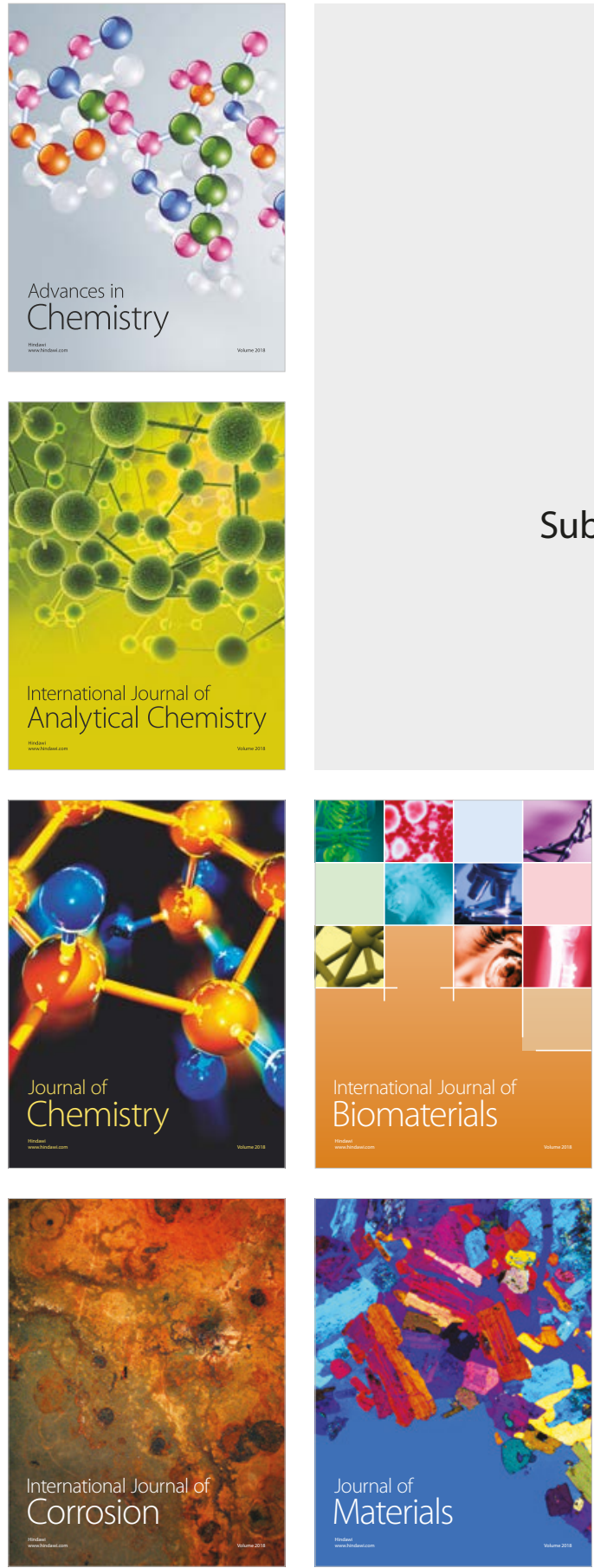

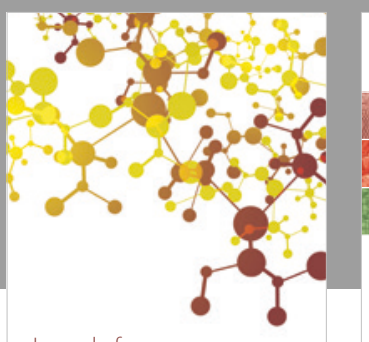

Journal of

Applied Chemistry
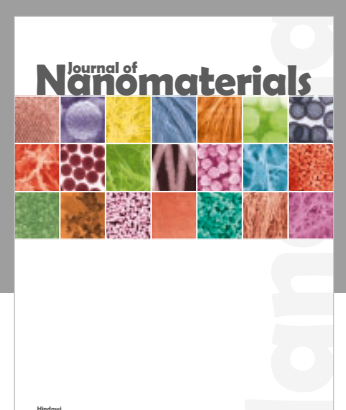

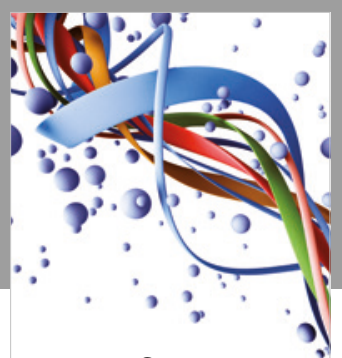

Scientifica

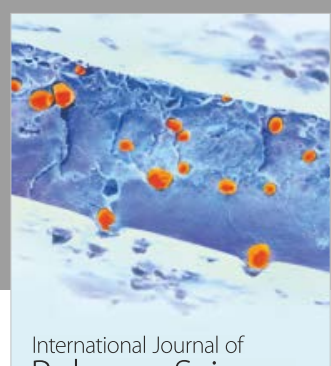

Polymer Science

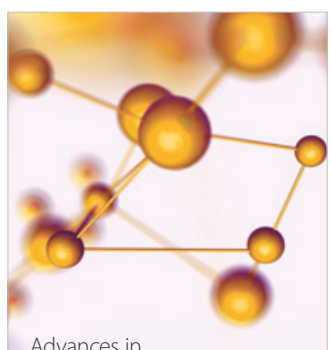

Physical Chemistry
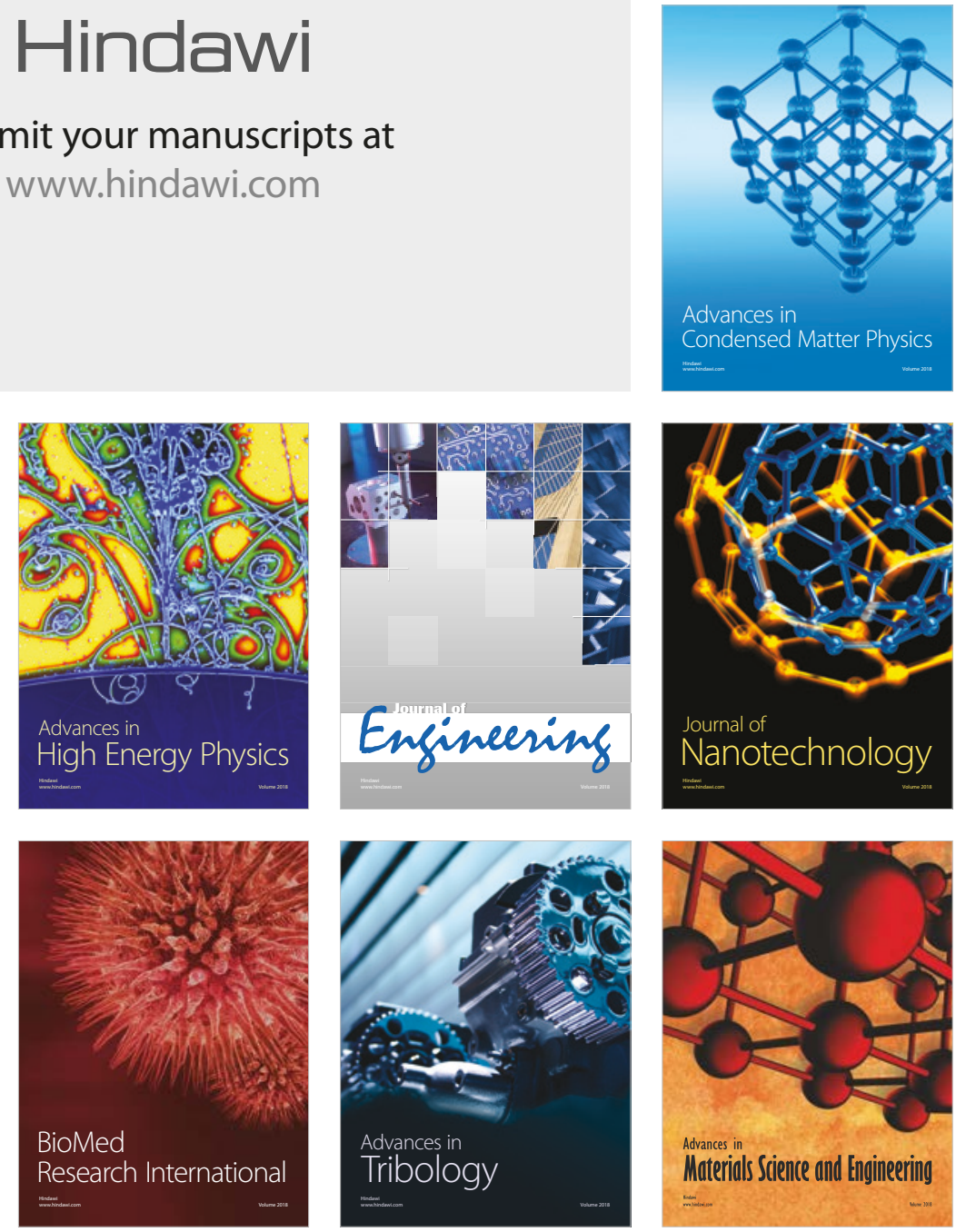